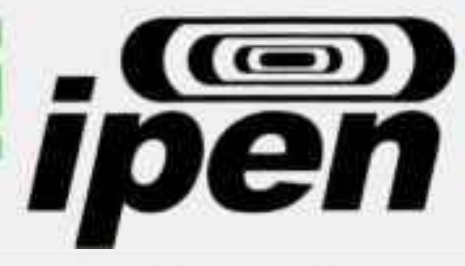

AUTARQUIA ASSOCIADA À UNIVERSIDADE DE SÃO PAULO

\title{
DESENVOLVIMENTO E CARACTERIZAÇÃO DE UM GEL ALANIMA PARA APLICAÇÃO NA MEDIDA DA DISTRIBUIÇÃO DA DOSE DE RADIAÇÃO USANDO A TÉCNICA DE ESPECTROFOTOMETRIA
}

ERICK YUKIO MIZUNO

Dissertação apresentada como parte dos requisitos para obtenção do Grau de Mestre em Ciências na Área de Tecnologia Nuclear - Aplicações.

Orientadora:

Dra. Lelícia L.C. Rodrigues 


\section{Instituto de Pesquisas Energéticas e Nucleares}

Autarquia Estadual vinculada à USP e gerenciada pela CNEN

DESENVOLVIMENTO E CARACTERIZAÇÃO DE UM GEL DE ALANINA PARA APLICAÇÃO NA MEDIDA DA DISTRIBUIÇÃO DA DOSE DE RADIAÇÃO USANDO A TÉCNICA DE ESPECTROFOTOMETRIA

ERICK YUKIO MIZUNO

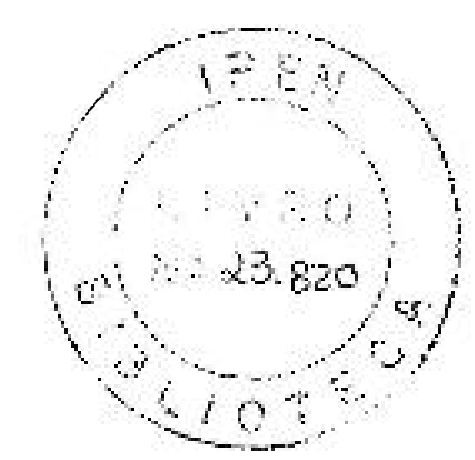

Dissertação apresentada como parte dos requisitos para obtenção do Grau de "Mestre em Ciências" na Área de Tecnologia Nuclear - Aplicações.

Orientadora:

Dra. Letícia Lucente Campos Rodrigues

SÃO PAULO 
Aos meus pais, Yoshinobu Mizuno Isaura de Oliveira

\author{
E também a \\ Wataru Hassegawa (Paulo) \\ Miyoko Kumagai \\ Mireni da Silva Primo \\ D. Antonieta Gonçalves Gilioli
}




\section{AGRADECIMENTOS}

Ao IPEN, na pessoa do Sr. Superintendente, Dr. Cláudio Rodrigues, pela oportunidade de executar este trabalho.

À minha orientadora, a Dra. Letícia Lucente Campos Rodrigues por todo o apoio, crença e dedicação dispensadas, não somente a mim, mas, também, a todos os seus orientandos e orientados. Obrigado também, pela amizade demonstrada!

Ao Dr. Orlando Rodrigues Júnior por todo o apoio e profissionalismo com que sempre me auxiliou no que necessitei, seja técnico-cientificamente falando, seja no que se refere à coordenação do grupo de trabalho.

Ao Dr. Alberto Saburo Todo pelas discussões sobre proteção radiológica e por algumas caronas também.

À Dra. Linda V.E. Caldas por ter me recebido neste Centro; CMR Centro de Metrologia das Radiações/IPEN.

Aos amigos do IPEN: Roberto Vicente, José Cláudio Dellamano, Sandra Bellintani, Tomie Hirayama por todo o apoio e, principalmente, amizade demonstrados até hoje.

Aos amigos Salomão, Sr. Luis, Linda (técnica química), Tereza, David e Manzolli e Vicente por tudo o que me ajudaram e/ou orientaram.

Ao incrivel trio Bete, Carlos e Hélio do CTR-IPEN por toda a dedicação, cuidado, presteza, precisão e profissionalismo com que sempre realizaram as irradiações e, mais do que isso, pela amizade demonstrada durante esse tempo.

À GELITA SOUTH AMERICA pelas amostras de gelatina suína de alta pureza e qualidade com as quais pude fazer os dosímetros. 
Aos caríssimos amigos, colegas de pós-graduação/iniciação científica, do IPEN, pessoas que tornaram mais agradável minha passagem por esta instituição. Assim, muito obrigado a vocês: Fábio Antunes, Giuliano Trigueiro, Ricardo Spolaor, Cristiane Cavinato, Eduardo Souto (Gaúcho), Eduardo Herédia e Maíra (desde os tempos da Física).

Ao ilustre professor Dr. Frank Herbert Quina do Departamento de Físico-Química do Instituto de Química da USP pelas discussões acerca de eventos químicos.

Aos servidores fixos ou terceirizados que tive o prazer de conhecer Tânia, Freire, Suzi, Alves, Raimundo, Gabriel, João Malandro e Araújo.

Aos meus amigos da família Esteves, Nelson, Vilani e Julio pelas palavras sinceras de incentivo e o apoio que sempre me deram.

Quase terminando, agradeço ao bom e 'velho' amigo, o tecnólogo Hendrigo Baldin, pelas várias discussões a respeito dos temas relacionados ao espalhamento de raios- $X$.

Agradeço, por fim, aos amigos anônimos que já me ajudaram e cuja lembrança o tempo levou, muito obrigado. 


\title{
DESENVOLVIMENTO E CARACTERIZAÇÃO DE UM GEL DE ALANINA PARA APLICAÇÃO NA MEDIDA DA DISTRIBUIÇÃO DA DOSE DE RADIAÇÃO USANDO A TÉCNICA DE ESPECTROFOTOMETRIA
}

\author{
Erick Yukio Mizuno
}

RESUMO

Este trabalho tem por objetivo a composição e caracterização de um dosimetro à base de DL-Alanina e Ferro-II em forma de gel para aplicações em dosimetria para campos de doses da radiação gama do Co-60 experimentadas em procedimentos de radioterapia. O aminoácido DL-Alanina é dissolvido em solução ácida contendo o Fe-ll e adicionado o gel. Procedeu-se a uma série de ensaios variando reagente a reagente e realizando procedimentos para avaliar 0 comportamento em função do tempo do gel dosimétrico obtido. Os espectros de absorção antes e após a irradiação apresentam máximos em $457 \mathrm{~nm}$ e $588 \mathrm{~nm}$, respectivamente. Esses dois picos correspondem aos comprimentos de onda de absorção das espécies Fe-II e Fe-III, respectivamente; estando ambas as espécies em equilíbrio. Com a irradiação, ocorre a formação de radicais que oxidam o Fe-ll em Fe-III, alterando com isso o balanço entre as duas espécies daí o aumento da concentração de Fe-III - fazendo com que mude a tonalidade do gel, sendo, portanto, possível de ser determinada a dose absorvida. Nas análises dos espectros e respectivas curvas dose-resposta observou-se que o gel dosimétrico apresenta linearidade no intervalo de doses entre 0,5 e $40 \mathrm{~Gy}$. A partir dos resultados obtidos de linearidade, estabilidade e menor dose detectável 0,3 Gy - conclui-se que o presente Gel Dosimétrico à base de DL-Alanina e Fe-II apresenta excelente potencial para a finalidade que é proposto, qual seja a determinação do campo de doses em radioterapia e futura aplicação como padrão na determinação desses campos, em 3D, utilizando-se a técnica de Imagem por Ressonância Magnética - IRM. 


\title{
DEVELOPEMENT AND CHARACTERIZATION OF AN DL-ALANINE GEL TO BE APPLIED IN THE MEASUREMENT OF THE DOSE DISTRIBUTION WITH THE SPECTROPHOTOMETRY TECHNIQUE
}

\author{
Erick Yukio Mizuno
}

\begin{abstract}
The aim of this work is to develop a DL-Alanine, Fe-ll based gel dosimeter to be applied in the dosimetry of the Co-60 gamma-radiation fields in the dose range of radiation therapy procedures. The aminoacid DL-Alanine is dissolved in an acid solution containing the Fe-ll and added to the gel. A series of essays was performed with different chemicals and different procedures were made to evaluate the behavior of the obtained dosimetric gel as function of the time. The absorption spectra, before and after the irradiation, present maximum in $457 \mathrm{~nm}$ and $588 \mathrm{~nm}$, respectively. These two peaks correspond to absorption wavelengths of the chemical species Fe-II and Fe-III, respectively, both species being in equilibrium. With the irradiation, the formation of the radicals that oxide the Fe-II into Fe-III occurs, altering the chemical balance of both species - hence the increase of the Fe-III - and causing the gel to change its tonality, in such a way that it is possible to determine the absorved dose. In the analysis of the spectra and respective dose-response curves it was observed that the dosimetric gel shows linearity in dose range of 0.5 to $40 \mathrm{~Gy}$. From the obtained linearity results, stability and lower detectable dose $-0,3 \mathrm{~Gy}$ - it is possible to conclude that the present DL-Alanine, Fe-Il based dosimetric gel presents an excellent potential to the application to which it is proposed, namely, the determination of the dose fields in radiation therapy and its future application as a standard in the determination of these fields, in 3D, using the Magnetic Resonance Imaging.
\end{abstract}




\section{SUMÁRIO}

1 INTRODUÇÃO

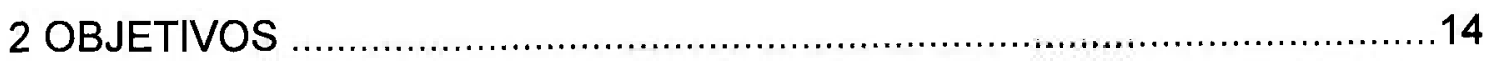

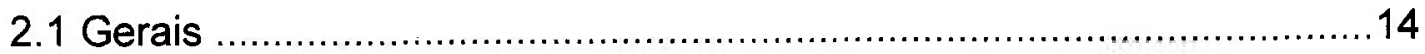

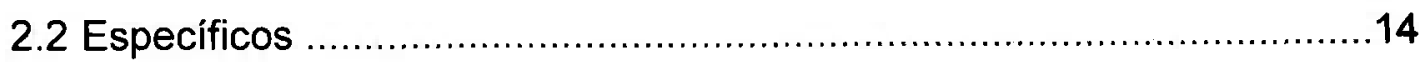

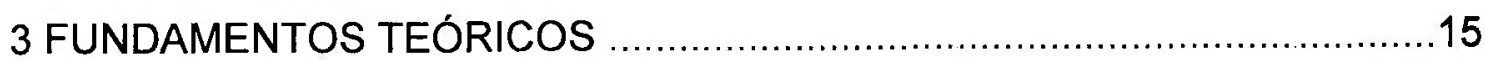

3.1 Conceito de Dosimetria ………………………………..............15

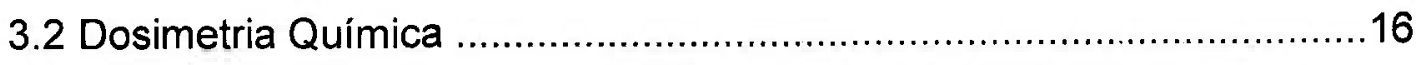

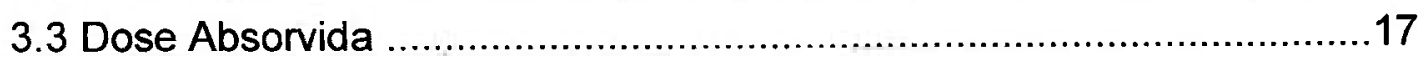

3.4 Influência de Fatores Externos em Dosimetria …………………...........19

3.4.1 Dependência Energética ........................................................19

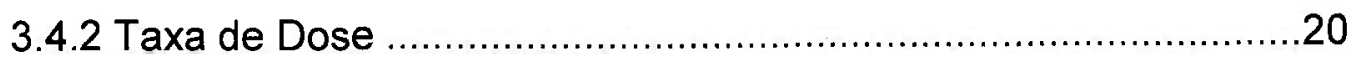

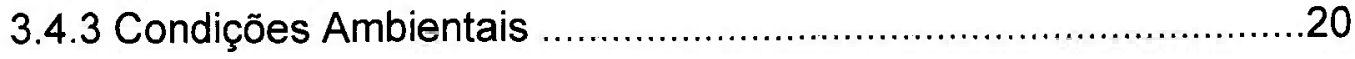

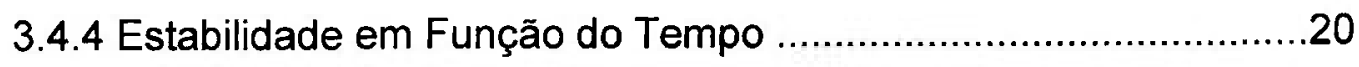

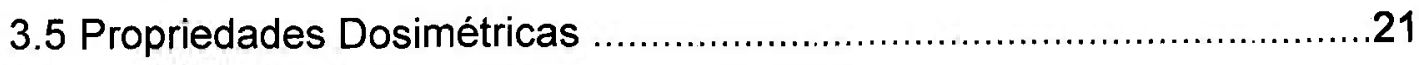

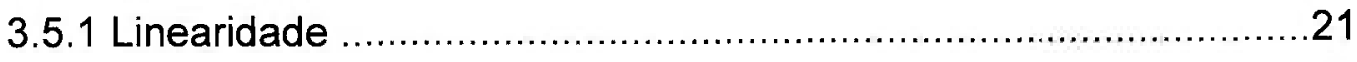

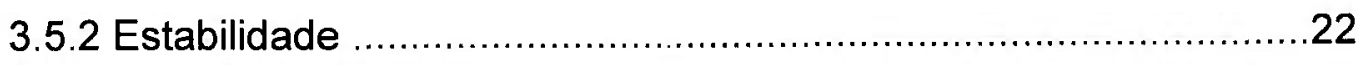

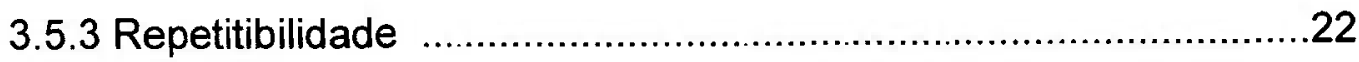

3.6 Características Gerais Desejadas ……..........................................23

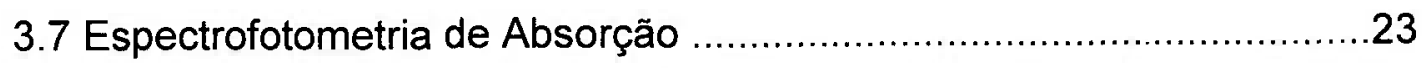

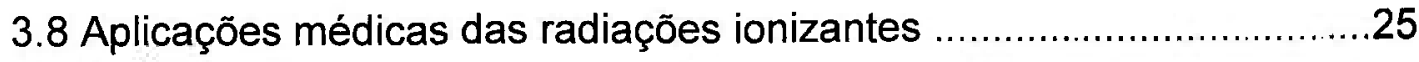

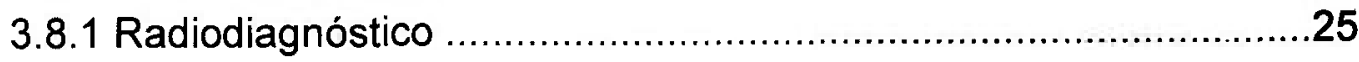

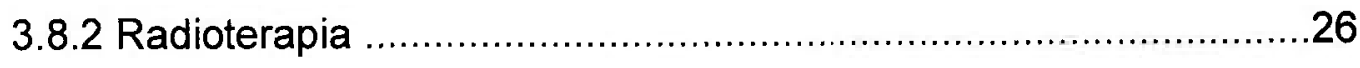

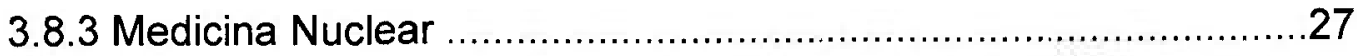

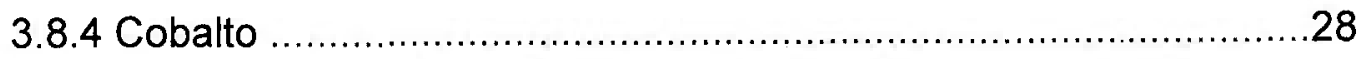

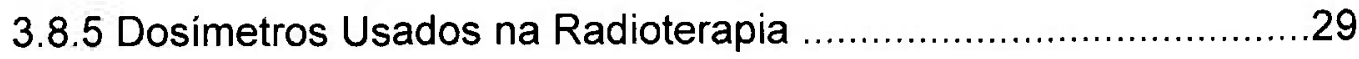

3.8.6 Dosímetro Fricke e Fricke Gel ......................................................

3.8.6.1 Imagem por Ressonância Magnética - IRM ..............................30

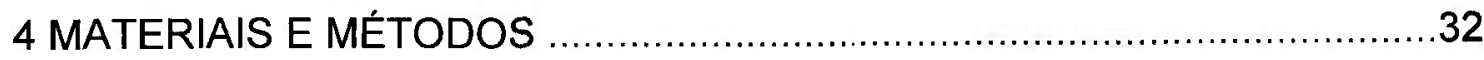

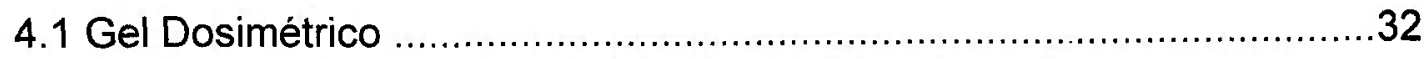

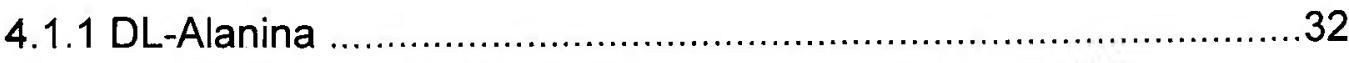

4.1.2 Sulfato Ferroso Amoniacal ...................................................32 


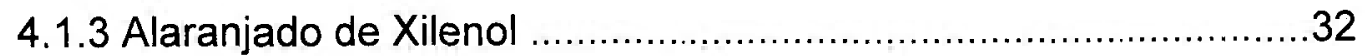

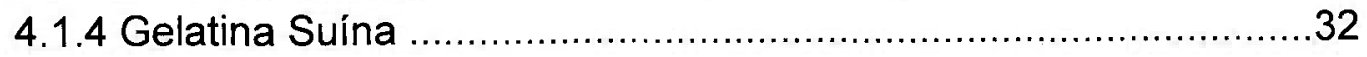

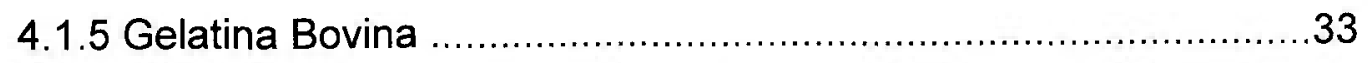

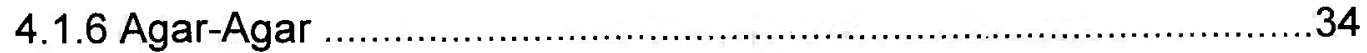

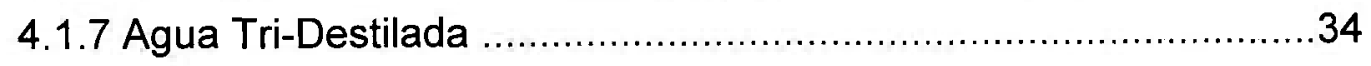

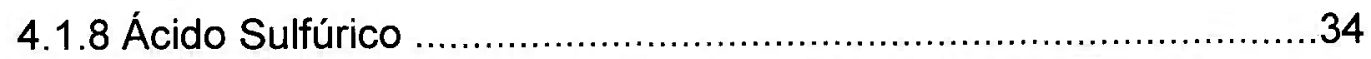

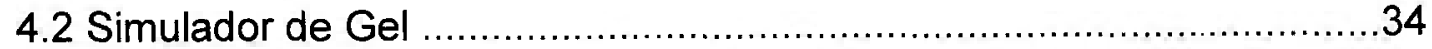

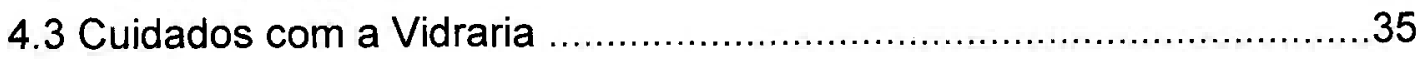

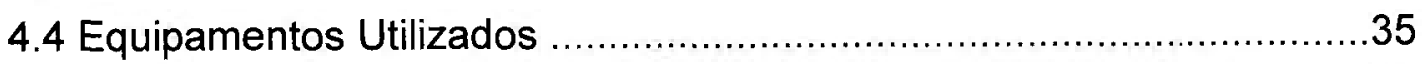

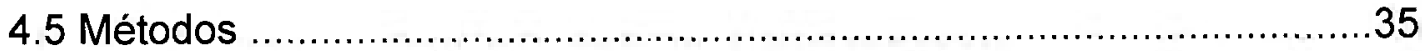

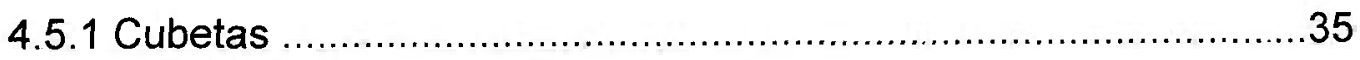

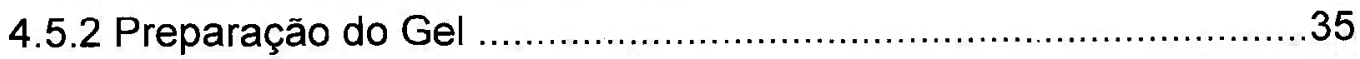

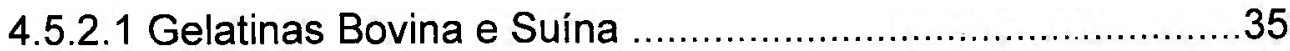

4.5.2.2 Gelatina à Base de Alga Marinha - Agar-Agar ...................36

4.5.3 Intervalo entre a elaboração do gel, a irradiação e as leituras ......37

4.5.4 Operação da balança de precisão …….........................................37

4.5.5 Operação do Espectrofotômetro Shimadzu UV 2101PC .............37

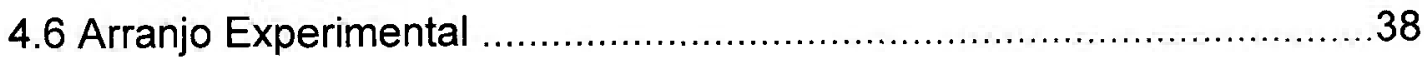

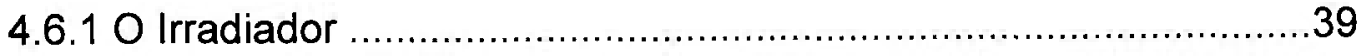

4.7 Método Espectrofotométrico Utilizando DL-Alanina .............................39

4.7.1 Uso do Branco na Segunda Cubeta .........................................40

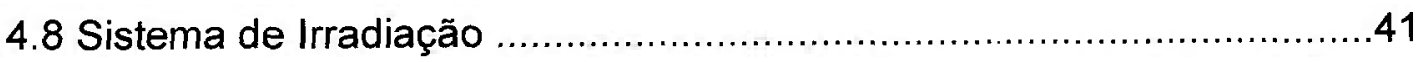

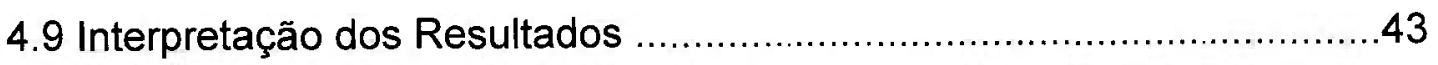

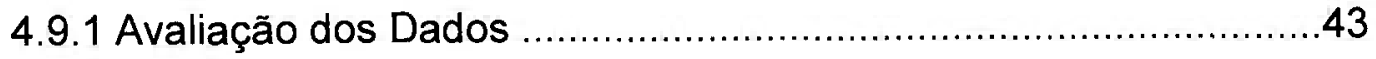

4.9.2 Tratamento dos Dados ......................................................43

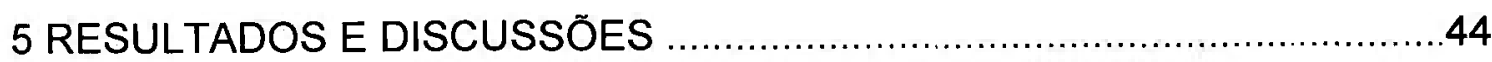

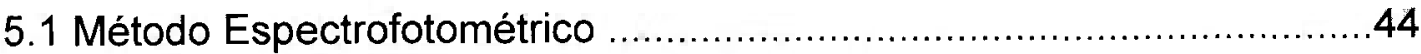

5.2 Estabilidade Mecânica do Gel (Consistência) .......................................46

5.2.1 Gelatinas Tipo Básica (Bovina) e Ácida (Suína) .........................46

5.2.2 Gelatina de Algas Marinhas - Agar-Agar ..................................48

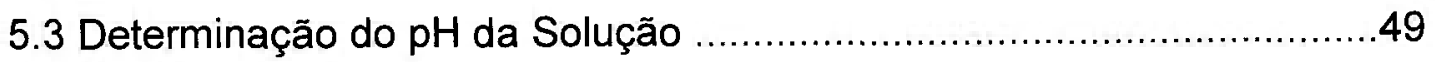

5.4 Determinação da Concentração de Sulfato Ferroso Amoniacal (Sal de Mohr)

5.5 Determinação da Concentração de DL-Alanina ....................................53 
5.6 Determinação da Concentração de Alaranjado de Xilenol .....................54

5.7 Ensaio Comparativo SEM DL-Alanina ...............................................54

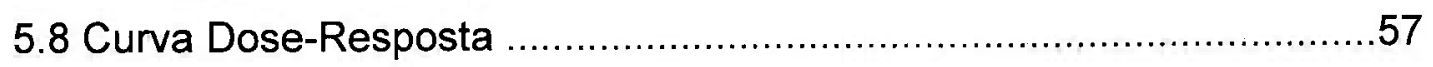

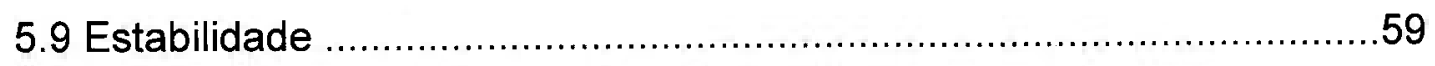

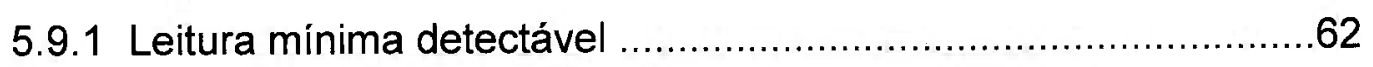

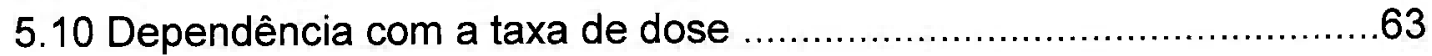

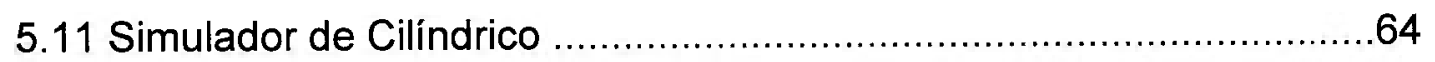

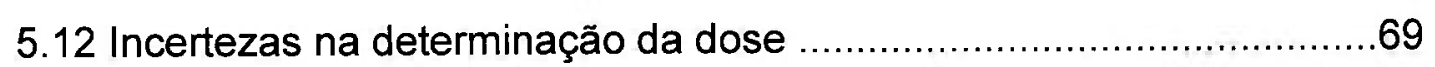

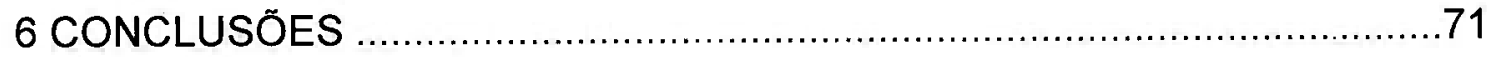

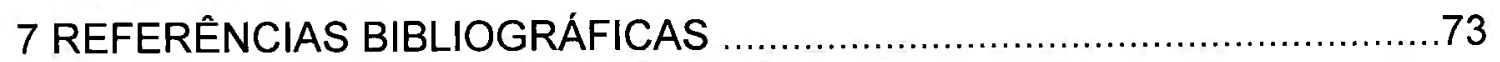




\section{INTRODUÇÃO}

A radiação ionizante é um meio efetivo de acelerar reações químicas e melhorar a qualidade de produtos naturais e sintéticos, oferecendo vantagens tecnológicas nunca antes obtidas.

A escolha dos processos industriais e das pesquisas avançadas que utilizam essas radiações depende de análises das qualidades do material, sendo necessária, em ambos os casos, a presença de um sistema dosimétrico seguro que possa garantir que o tratamento requerido foi corretamente aplicado.

Em especial, três processos importantes, como a esterilização de produtos de uso médico, a preservação de alimentos pela esterilização utilizando radiação gama e a radioterapia, estão diretamente associados à saúde pública.

Outras principais aplicações industriais da radiação, como a modificação de polímeros, a cura de revestimentos de superfícies e a irradiação de fios e cabos, que oferecem vantagens em relação aos sistemas convencionais, principalmente no aspecto ambiental, também necessitam de um controle da dose absorvida para que seja obtido o efeito desejado.

A dosimetria da radiação ionizante tem por finalidade a determinação da dose absorvida (Hubell, 1982) resultante de interação da radiação com o meio, além de assegurar que os resultados obtidos em laboratório possam ser reproduzidos em outros locais. Para isso, utilizam-se dosimetros, que são dispositivos com capacidade de fornecer informações que estejam direta e proporcionalmente relacionadas com a dose absorvida (Costa, 1994).

De forma mais especifica, quanto à utilização de radiação ionizante na área médica, os recentes avanços na tecnologia de tratamentos com radiação, tais como "gamma knife" e radiocirurgias, forneceram meios alternativos para os médicos tratarem pacientes com tumor de cérebro e outros tipos de tumores, que 
não podem ser efetivamente tratados pelos procedimentos convencionais de terapia com radiação.

O sucesso da terapia com radiações ionizantes depende de quão próximo está o valor da dose administrada ao paciente, daquela prescrita. Desse modo, uma maneira de se comparar as duas doses absorvidas é através da dosimetria, que é a quantificação da dose absorvida em um ponto ou volume alvo.

Com o crescimento do emprego da radiação ionizante na área médica e o aumento das doses aplicadas nos procedimentos médicos, a demanda por um mapeamento tridimensional da distribuição das doses também aumenta.

Os métodos convencionais disponiveis para avaliação da dose absorvida em um meio incluem as câmaras de ionização (Attix et al, 1963), dosímetros termoluminescentes (TL) (Portal, 1981) e filmes radiocrômicos (Van Bree Nam, 1994), bem como simulação por computador empregando Método de Monte Carlo (Moraes, 2006). Todavia, os métodos experimentais não apresentam natureza tridimensional (3D) para a medida, e muitas vezes, empregam materiais dosimétricos que não possuem boa equivalência com o tecido $e$, portanto, não sendo adequados para medidas 3D de dose (Horowitz, 1994).

Atualmente existem várias aplicações para os métodos dosimétricos que determinam precisamente a variação espacial da dose de radiação depositada em um meio absorvedor. Por exemplo, técnicas de radioterapia que utilizam campos combinados e movimentos complexos das fontes de radiação, os quais produzem distribuições de dose que são difíceis de prever precisamente sem o uso extensivo de cálculos computacionais e calibrações.

Apesar da existência de métodos algorítmicos - como as simulações computacionais existente nos softwares dos equipamentos de teleterapia - que simulam e prevêem a distribuição do campo de dose no paciente, é indispensável a aferição do quão próxima está a dose efetivamente recebida daquela prescrita para o tratamento. A técnica da dosimetria tridimensional tem se mostrado bastante promissora na determinação, prática, da distribuição de doses. 
A dosimetria tridimensional (Tsai, 1999; Olsson, 1989) pode ser realizada de duas maneiras no que se refere às dimensões dos detectores.

Dosimetria discreta - através do posicionamento em um simulador desses detectores que possuem um tamanho físico mensurável tipo TLD Thermo Luminescet Dosimeter - , por exemplo, que possuem seção transversal de $1 \mathrm{~mm}^{2} \mathrm{e}$, após serem irradiados no interior do simulador, são avaliados (medidos) um a um a fim de se obter, após adequado processamento computacional, o campo da irradiação. Isso é feito através do processamento das isolinhas de doses que são, em seguida, sobrepostas paralelamente formando-se um volume espacial.

Dosimetria contínua - feita utilizando-se um meio contínuo à base de gel; apresenta um potencial de definição da dose de radiação absorvida mais preciso, visto que a variação na intensidade da radiação em função da profundidade que penetra no tecido é variável continuamente, sendo mais precisamente determinada através de um dosímetro do tipo gel, onde ocorrem transformações químicas (Olsson, 1989) que tornam possivel a determinação da variação de dose de radiação em função da profundidade no tecido (Spinks, 1964).

No caso da dosimetria gel ou gel/polímero ocorre a variação na concentração de algum componente químico, ocasionando alteração no equilíbrio químico entre seus componentes e/ou a formação de centros de cor; o que permitirá o emprego da técnica de leitura de absorção óptica.

$\mathrm{Na}$ dosimetria química, contínua, tem-se o uso do dosímetro Fricke tradicional (Fricke \& Morse, 1929), do Fricke Gel, ou do Fricke modificado (Bero, 2001; Cavinato, 2006), Géis dosimétricos à base de ín ferroso-alanina (Fe-II) (Mizuno, 2006) e os Géis Poliméricos (Baffa et al, 2006). A técnica geralmente empregada para a avaliação da dose é a absorção óptica.

A grande vantagem desses materiais reside no fato de que esta técnica de determinação de curvas de isodoses pode ser associada ao método de leitura 
da Ressonância Magnética Nuclear - RMN (Chu, 2001; Olsson, 1989), técnica diagnóstica de grande gama de possibilidade de visualização de volumes em análise por imagem; seja por cortes antero-posterior, sagitais, longitudinais ou por camadas radiais.

A dosimetria, desta maneira, poderia ser feita observando-se diferentes cortes de um volume a fim de se estudar a distribuição de doses de radiação em diferentes planos de leitura, por exemplo.

A alanina é um material de número atômico efetivo baixo, $Z=48$, equivalente ao do tecido para efeitos da interação da radiação ionizante com a matéria, de baixo custo e de fácil obtenção no mercado nacional. O dosímetro alanina/RPE é um dosímetro padrão para doses (Galante, 1999) nível de aplicação industrial.

Existem, também, estudos da aplicação da solução de alanina + alaranjado de xilenol (Costa, 1994) na dosimetria química, empregando a técnica de espectrofotometria de absorção na região UV-Visível.

Devido à grande aplicabilidade desse material na dosimetria de doses altas, neste trabalho é avaliada a viabilidade de um gel de alanina para a determinação de dose empregando a técnica de espectrofotometria de absorção.

Prevê-se a aplicação desse novo sistema dosimétrico para a determinação de doses através da técnica de Ressonância Magnética Nuclear RMN, numa oportunidade futura. 


\section{OBJETIVOS}

\subsection{Gerais}

Este trabalho visa a obtenção de um $\mathrm{Gel}$ Dosimétrico baseado em DL-Alanina e Ferro II. Objetiva-se um sistema dosimétrico capaz de determinar curvas de isodose com precisão suficiente para sua aplicação em procedimentos de simulação em Teleterapia e Braquiterapia que utilizem a radiação gama do Cobalto 60 e que seja confiável, reprodutivel e barato, não sujeito a decaimento rápido do sinal devido à luz ou temperatura e que seja, ao mesmo tempo, consistente em temperatura ambiente, sem a necessidade de ser mantido constantemente sob refrigeração.

\subsection{Especificos}

- Desenvolver e um material em forma de gel para medida de doses no intervalo de doses de radioterapia;

- Pesquisar diferentes materiais geleificantes e o efeito da variação da concentração dos diferentes componentes da solução;

- Estudar a reprodutibilidade e estabilidade do gel obtido empregando a técnica de espectrofotometria de absorção;

- Efetuar os testes de desempenho do material para aplicação na dosimetria da radiação gama do Co-60.

- Desenvolver um objeto simulador de pescoço, à base de gel, para efetuar medida da distribuição de doses;

- Avaliar a incerteza na determinação da dose. 


\section{FUNDAMENTOS TEÓRICOS}

\subsection{CONCEITO DE DOSIMETRIA}

A determinação correta da dose absorvida é de grande importância na utilização das radiações ionizantes. Assim, organizações internacionais elaboram e recomendam a utilização de protocolos de dosimetria para que certos cuidados sejam tomados e para que se possa determinar a dose absorvida nos diversos materiais (ICRU, 1993).

Entre os vários tipos de dosimetros que podem ser utilizados na determinação da dose absorvida, alguns são considerados como absolutos ou padrões primários. Nesse caso, ele é definido como um dosímetro de alta qualidade metrológica, com o qual pode-se determinar a dose no próprio volume sensivel do detector, sem requerer calibração em um feixe de radiação conhecido. Como exemplo tem-se o calorimetro, o Dosímetro de Fricke (Fricke \& Morse, 1927; Chu, 2001).

Os dosimetros de referência, ou padrões secundários, são suficientemente precisos e estáveis, podendo ser calibrados por um padrão primário. Como exemplo, tem-se o etanol clorobenzeno e a alanina, dentre outros (IAEA, 1994).

A maioria dos dosímetros de referência também pode ser utilizada como padrão de transferência. Nesse caso, o dosímetro deve ser estável, reprodutivel e possuir propriedades de absorção semelhantes àquelas dos materiais irradiados. Como o dosímetro de transferência muitas vezes não é avaliado após a irradiação, as condições de temperatura e umidade durante a irradiação, o transporte e o armazenamento devem ser observados (IAEA, 1994).

Existem, ainda, os dosimetros de rotina, que são usados diariamente nas instalações ou laboratórios que utilizam a radiação. Esses sistemas devem ser calibrados freqüentemente, já que são instáveis. Como exemplo, os filmes plásticos, vidros e soluções químicas (IAEA, 1994). 


\subsection{DOSIMETRIA QUÍMICA}

A dosimetria química consiste na determinação da dose absorvida a partir das medidas da variação das concentrações dos reagentes químicos na solução, induzidos pela radiação ionizante. Quando a radiação interage com um meio, esta pode ser convertida na produção de íons. Os íons podem favorecer reações com outras moléculas, produzindo radicais livres e íons secundários, que podem reagir e formar produtos químicos estáveis.

A dosimetria química teve início em 1927 com Hugo Fricke e Stern Morse, que iniciaram um estudo sobre a ação química de uma solução de sulfato ferroso para realização de medidas de dose absorvida para raios $X$ (Fricke \& Morse, 1927).

O dosímetro de Fricke é baseado na oxidação do ion ferroso, Fe-II, em ín férrico, Fe-III, na presença de oxigênio, sob influência da radiação ionizante. No presente trabalho e em outros, foi utilizada a radiação gama do Co-60 (Spinks, 1964).

Hugo Fricke propôs este sistema pela primeira vez em 1929 utilizando uma solução a base de ácido sulfúrico sob a irradiação de raios-x de tal forma que a resposta fosse a mesma das câmeras de ionização (Anderson, 1993).

O principio de funcionamento é relativamente simples; a radiação ionizante deposita parte de sua energia no volume dosimétrico, pares eletron-ion são formados pela reação (Dainton, 1964)

$$
\mathrm{e}^{-}+\mathrm{H}^{+} \rightarrow \mathrm{H}
$$

Em solução ácida - alta concentração de ion de hidrogênio - esta reação ocorre mais rapidamente quanto maior for a concentração de oxigênio (Dainton, 1964; Palm, 2000). A reação é a que segue: 


$$
\mathrm{H}+\mathrm{O}_{2(\mathrm{aq})} \rightarrow \mathrm{HO}_{2}
$$

$$
\mathrm{HO}_{2}+\mathrm{Fe}^{2+} \rightarrow \mathrm{HO}_{2}^{-}+\mathrm{Fe}^{3+} .
$$

Uma vez que todos os oxigênios presentes dissolvidos na solução forem utilizados, o radical $\mathrm{HO}_{2}$ não mais poderá ser formado, o que inibirá a oxidação do íon ferroso em íon férrico, fazendo com que a reação pare de ocorrer e alcance uma situação de equilibrio químico.

Agora, a partir do dosimetro de Fricke, surgem propostas de dosimetria química buscando cada vez mais praticidade e precisão em seus resultados, os quais se encontram fortemente dependentes do desenvolvimento de técnicas de avaliação por imagem mais e mais sofisticadas e precisas. Como é o caso dosimetria utilizando a técnica diagnóstica por imagem de Ressonância Magnética Nuclear - RMN (Tsai, 1999; Anderson, 1993).

\subsection{DOSE ABSORVIDA}

Define-se a dose absorvida D como (Attix \& Roesch, 1968):

$$
\mathrm{D}=\frac{d \varepsilon}{d m}
$$

Onde: $\quad d \varepsilon$ é a energia média depositada pelo feixe de radiação ionizante na matéria de volume $d m$.

A unidade de medida da dose absorvida é gray, representada por Gy e cuja unidade no $\mathrm{Sl}$ é o J . $\mathrm{kg}^{-1}$. Vale observar que ainda é utilizada a unidade rad para a medida da dose absorvida, ainda que mais antiga, e tem a seguinte correspondência: 


$$
1 \mathrm{~Gy}=1 \mathrm{~J} \cdot \mathrm{kg}^{-1}=100 \mathrm{rad}
$$

No presente trabalho, foi observado o intervalo de doses de radiação para terapia, no intervalo de doses entre 0,5 e $20 \mathrm{~Gy}$.

A dose absorvida por certos materiais depende de fatores importantes, como segue:

- a atividade e a geometria da fonte;

- a distância entre a fonte e o material a ser irradiado;

- o tempo de irradiação;

- a composição e a densidade do material;

- a geometria do material.

A dose absorvida em um material é medida por um dosímetro. Quando o dosímetro é colocado juntamente com o material durante a irradiação, ele constitui uma descontinuidade ou uma "cavidade" no meio. Geralmente, ele difere do material em número atômico e densidade e, por isso, diferirá também nas propriedades de absorção. Por esta razão, faz-se necessária a correlação dessas doses obtidas em diferentes meios e dada por (Attix \& Roesch, 1968):

$$
\mathrm{D}_{\mathrm{m}}=0,876 A\left[\frac{\left(\mu_{e n} / \rho\right)_{M}}{\left(\mu_{e n} / \rho\right)_{A r}}\right] \cdot X
$$

Onde: $D_{m}$ é a dose absorvida, $A$ é a razão das fluências, $X$ é a exposição em Roentgens, $\left(\mu_{e n} / \rho\right)_{M}$ e $\left(\mu_{e n} / \rho\right)_{A r}$ são os coeficientes de absorção de energia pelo meio e pelo ar, respectivamente.

A exposição $X$ é a medida do número de ionizações por kilograma no ar ocorridas devido à exposição à radiação ionizante. 


\subsection{INFLUÊNCIA DE FATORES EXTERNOS EM DOSIMETRIA}

Devido às vantagens tecnológicas obtidas com o uso das radiações ionizantes e pelo fato de a medida da dose absorvida não ser direta e tecnicamente simples mas, envolver incertezas em cada passo da padronização, tornou-se necessária a implantação de um controle de qualidade aceito internacionalmente.

Desta forma, desde 1977 a IAEA (International Atomic Energy Agency) implantou um programa de padronização de doses em escala internacional, a fim de promover a dosimetria como medida de controle de qualidade durante 0 processo por irradiação e também desenvolver novas técnicas dosimétricas (ICRU, 1993) (IAEA, 1994).

Alguns sistemas dosimétricos são utilizados indiretamente na medida da dose absorvida, por satisfazerem os requisitos para um controle diário, porém, são dependentes de um série de fatores que não são controlados facilmente. Dentre eles destacam-se:

- dependência energética;

- taxa de dose;

- condições ambientais;

- estabilidade em função do tempo.

\subsubsection{DEPENDÊNCIA ENERGÉTICA}

A dependência energética pode causar incertezas na medida da dose absorvida, principalmente quando um dosímetro é calibrado sob condições especificas de energia e geometria de irradiação e é utilizado sob condições que não sejam exatamente as mesmas daquelas de sua calibração.

Existem, porém, situações nas quais a dependência energética é inerente ao sistema dosimétrico, tendo uma resposta que varia em função da energia da radiação incidente. 


\subsubsection{TAXA DE DOSE}

A taxa de dose é um outro fator de importante contribuição, indesejada, que deve ser observado na determinação da dose absorvida, assim como na ocasião da calibração de um sistema dosimétrico.

Alguns sistemas dosimétricos comportam-se de maneiras diferentes em função de diferentes taxas de doses às quais estejam expostos. Este comportamento, dependente da taxa de dose, varia de sistema para sistema dosimétrico, cabendo aqui, tão somente, atentar para esta importante característica que deverá ser analisada quando da padronização de um sistema dosimétrico.

\subsubsection{CONDIÇÕES AMBIENTAIS}

As condições ambientais são determinantes quando se trata de dosimetria química, principalmente. São fatores ambientes mais relevantes a temperatura, iluminação, concentração de oxigênio, difusão, dentre outros menos freqüentes. A importância reside no fato de as reações quimicas não serem estáticas, ou seja, elas ocorrem e continuam ocorrendo em velocidade que depende destas condições ambientais.

Desta forma, um sistema dosimétrico a seco (não aquoso) será mais estável, ao passo que um aquoso, será menos estável (Dainton, 1964) pelo fato de haver a presença de água o que favorecerá a recombinação constante dos radicais, formando-se outras espécies e variando-se uma leitura inicial. Este fenômeno recebe o nome de Recombinação de lons (ou radicais) e não é observada em sistemas a seco, dada a ausência de água.

\subsubsection{ESTABILIDADE EM FUNÇÃO DO TEMPO}

A maioria dos dosímetros utilizados depende da medida de uma espécime estável ou relativamente estável, a qual é formada como resultado de uma série de reações envolvendo íons, radicais livres, reações intermediárias e de competição que ocorrem após a irradiação e antes que o produto mensurável seja formado. Desta forma, percebe-se que, inevitavelmente, haverá um aumento na resposta de absorção óptica em função do tempo. Aumento este ocasionado 
principalmente devido a existência de recombinações provocadas, por sua vez, também, pelos fatores apontados, quais sejam a temperatura, concentração de oxigênio, iluminação, dentre outras.

Incertezas adicionais na determinação da dose são introduzidas por erros instrumentais ditos erros sistemáticos que são, por exemplo, a estabilidade do sistema de medida, medição incorreta dos reagentes, falta de manutenção e calibração de instrumentos e o erro de percepção e tempo de reação humanos.

Fatores como a direção de incidência da radiação, atenuação, composição atômica, tamanho e tipo do dosímetro também contribuem para aumentar as incertezas. Porém, os mesmo são facilmente minimizados pela escolha do dosímetro adequado em tamanho e com características semelhantes às do meio irradiado, através da análise do qual, quer-se determinar a dose de radiação absorvida.

\subsection{PROPRIEDADES DOSIMÉTRICAS}

As principais propriedades dosimétricas que um material deve apresentar para ser empregado com sucesso na dosimetria das radiações são:

- Linearidade;

- Estabilidade;

- Reprodutibilidade.

\subsubsection{LINEARIDADE}

Para ser útil, um dosímetro deve ter uma sensibilidade adequada em um intervalo de dose absorvida, de modo a fornecer uma resposta linear dentro dos limites estabelecidos e facilitar os cálculos e a interpretação dos resultados.

O limite inferior, muitas vezes, é imposto por limitações do equipamento utilizado nas leituras, o qual é responsável, freqüentemente, por respostas espúrias causadas pela interferência devido ao ruido ocasionado por outras fontes como, por exemplo, radiação ambiental e variações de temperatura. 
O limite superior da região útil do dosímetro pode ser imposto por condições externas ao instrumento, tais como leituras fora da região de sensibilidade do equipamento ou por danos de irradiação causados aos dosímetros. Para doses acima desse limite a resposta do dosímetro não se altera mais ou apresenta um crescimento visivelmente tendendo a se estabilizar até que não mais se altere com o aumento da dose, caracterizando uma região de saturação.

\subsubsection{ESTABILIDADE}

A estabilidade de um dosímetro caracteriza-se pela mudança, ou não, da resposta dosimétrica em função do tempo decorrido entre a irradiação e o momento da leitura.

A diminuição da estabilidade pode ser causada por condições adversas de armazenamento. Assim, um dos requisitos mais importantes nas análises dosimétricas é que o dosimetro seja o mais insensível possivel às mudanças extremas das condições ambientais, ou então, que permita a correção dos erros causados por esses fatores.

\subsubsection{REPETITIBILIDADE}

O ideal é que o material dosimétrico apresente uma resposta reprodutível nas mesmas condições de análise. A repetitibilidade está associada aos conceitos de precisão.

A precisão pode ser estimada a partir de dados obtidos em medidas repetidas e é usualmente estabelecida em termos do desvio padrão da média. Uma alta precisão é associada a um pequeno desvio padrão. Ou seja, quanto mais medidas, desde que reprodutiveis, mais preciso o resultado.

No caso de uma única medida, a precisão indica quão próxima ela está do valor esperado da grandeza que está sendo medida. Igualmente, a precisão do valor médio de um grupo de medidas realizadas sob as mesmas condições expressa a probabilidade de sua concordância com o valor esperado. 
Exatidão é uma palavra usada para descrever o quanto o valor experimental está próximo do valor verdadeiro da grandeza. Quanto menor for o erro total, tanto maior é a exatidão do resultado. Em outras palavras, um valor muito exato é um valor muito próximo do valor verdadeiro.

\subsection{CARACTERISTICAS GERAIS DESEJADAS}

De um modo geral, espera-se que o sistema escolhido como dosímetro seja fácil e simples de usar, tenha custo inicial e operacional satisfatórios e apresente propriedades de absorção semelhantes àquelas dos produtos irradiados.

Vale aqui salientar que a referida propriedade de absorção semelhante melhor ocorre quanto mais o número atômico efetivo do meio dosimétrico se aproximar do número atômico efetivo do produto irradiado.

\subsection{ESPECTROFOTOMETRIA DE ABSORÇĀO}

A espectrofotometria é um método analítico que se utiliza da transmissão ou absorção de comprimentos de onda com energias que variam continuamente na faixa do visível ao ultra-violeta (Gupta et al, 1982, 1985, 1986).

Atende ao princípio da Lei de Beer-Lambert representado, esquematicamente por:

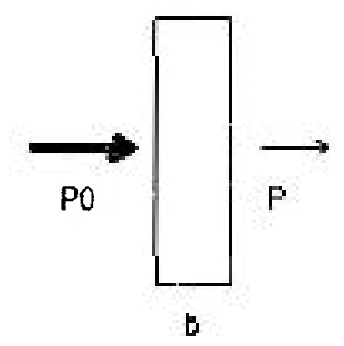

b representa a espessura a ser percorrida pelo feixe de luz dentro da amostra. 
E cuja relação matemática é dada pela expressão:

$$
A=\log _{10} \frac{P_{0}}{P}
$$

Onde:
A é o valor da Absorbância da amostra;
$\boldsymbol{P}_{0}$ é o valor da intensidade luminosa injetada na amostra;
$\boldsymbol{P}$ é o valor da intensidade luminosa emergente da amosta.

Para a avaliação das propriedades ópticas do material foi empregado um espectrofotômetro no intervalo de comprimentos de onda de 190 até $900 \mathrm{~nm}$. Este método utiliza a mudança na cor do meio que se deseja analisar. Mudança ocasionada pela ionização induzida pela radiação no meio dosimétrico e conseqüente formação de centros de cor.

Esses centros de cor são resultado de recombinações dos radicais formados com o Fe-II, de cor característica, ionizando-o em Fe-III, cuja estrutura associada ao Alaranjado de Xilenol possui cor diferente daquela devida à, somente, presença do Fe-II.

A formação de radicais no meio dosimétrico que promove as reações químicas responsáveis pela alteração na tonalidade da amostra, o que permite sua avaliação por esta técnica.

No caso do dosímetro Fricke, esses radicais, quando dissolvidos em solução contendo sulfato ferroso amoniacal, alaranjado de xilenol e ácido sulfúrico, oxidam os íons ferrosos (Fe-II) em íons férricos (Fe-III) que, combinado ao alaranjado de xilenol, forma um complexo de diferente tonalidade na solução inicial (GUPTA, B.L.; et al, 1982, 1985, 1986) (Van Laere, 1991; Gay, 1999; Van Laere et al, 1999, 1999a).

A absorbância do complexo é medida por espectrofotometria de absorção. A mudança na absorbância é devida a um aumento da concentração dos íons férricos, o que ocasiona a mudança na cor, e é uma função da dose 
absorvida. Embora a parte quimica e física da reação não seja completamente entendida, um esquema da reação foi proposto por Van Laere (Van Laere et al, 1999, 1999a), através do qual é possivel explicar qualitativamente as interações observadas.

A reação de oxidação efetiva na qual o sistema é baseado depende fortemente do oxigênio presente na solução.

\subsection{APLICAÇÕES MÉDICAS DAS RADIAÇÕES IONIZANTES}

\subsubsection{Radiodiagnóstico'}

Alguns dos mais interessantes desenvolvimentos na geração de imagens para a Medicina ocorreram no campo da tomografia, que possibilita a formação de imagens de uma parte específica do corpo, tanto por meio da incidência externa de raios- $X$, quanto da injeção endovenosa ou ingestão de radioisótopos associados a fármacos alvo-específicos.

Há também a tomografia computadorizada axial, (CAT Computadorized Axial Tomography), técnica na qual ocorre a incidência de feixes de raios- $X$ na região de interesse. Para cada feixe é possivel determinar a perda de intensidade e, portanto, o nivel de absorção por uma determinada direção. Assim, podem ser formadas imagens bidimensionais da região de interesse.

Outro exemplo é o da Tomografia por Emissão de Pósitrons (PET Positron Emission Tomography), na qual um isótopo emissor de pósitrons é introduzido na área a ser estudada. Seu decaimento, através da emissão de um par de fótons anti-paralelamente, possibilita a formação de imagens, em vários aspectos mais interessantes que aquelas produzidas pelo CAT, visto que a PET pode revelar também efeitos dinâmicos, tais como o fluxo de sangue. Aplicações interessantes para 0 mapeamento funcional do cérebro são possíveis por esse meio.

1. http://ipnoo01_iridium.com.br 
Outra interessante técnica diagnóstica, algo semelhante à PET é o SPECT (Single Photon Emission Computadorized Tomography) também baseada na administração de radiofármacos a pacientes e posterior leitura através da detecção dos fótons emitidos.

\subsubsection{Radioterapia ${ }^{2}$}

O uso básico das radiações ionizantes na terapia é para a destruição de tecidos indesejáveis que não funcionam corretamente, tumores cancerigenos ou da glândula tireóide hiper ativa. Isso é obtido através do uso das radiações ionizantes.

De maneira resumida, a destruição desses tecidos é feita através dos seguintes passos:

(1) as radiações incidentes ionizam átomos de moléculas do material irradiado;

(2) as moléculas ionizadas participam de uma reação química, que dá lugar a radicais livres ou outras moléculas excitadas (ver item 3.2);

(3) os radicais livres podem ser incorporados dentro de uma estrutura biológica complexa (no nivel molecular) e alterar suas funções, podendo levar horas e até anos para que os efeitos dessa mudança biológica se tornem aparentes. No caso, o efeito desejado é a destruição celular, de um tecido cancerígeno.

É possivel ter uma ação direta pela radiação nas moléculas sensiveis biologicamente, seguindo o passo (2); uma vez que o corpo humano é formado aproximadamente por $70 \%$ em massa de água, é mais provável que a radiação produza eventos ionizantes em moléculas de água. Assim, a molécula de água pode ser ionizada pela incidência de radiação, ocasionando a formação dos radicais livres que irão promover a destruição do tecido alvo.

2. http://ipn0001.iridium.com.br 


\subsubsection{Medicina Nuclear ${ }^{3}$}

Os radioisótopos produzidos em reatores nucleares ou aceleradores de partículas têm sido freqüentemente associados às substâncias químicas na formação de compostos chamados de radiofármacos, os quais se associam a determinado tecido ou órgão humano objetivando o diagnóstico de doenças. Há várias técnicas de utilização dessas substâncias, sendo a cintilografia a mais conhecida e utilizada.

A cintilografia utiliza a propriedade do radiofármaco de ter um comportamento biológico que é idêntico ao de similares não radioativos, como é o exemplo da concentração de iodo, radioativo ou não, na tireóide. Após o tempo necessário para a fixação do composto no órgão a se pesquisar, imagens são produzidas em câmaras de cintilação ou por outros aparelhos de detecção de radiação. A deteç̧ão gera uma imagem onde os pontos mais claros são aqueles que emitem maior radiação.

Além da imagem, a concentração e a captação do radiofármaco também são fatores para o diagnóstico feito pelo médico. A utilização desse tipo de imagem revolucionou as técnicas de diagnóstico, pois, diferente das outras formas de imagem, como radiografia simples, a detecção de radiofármacos avalia o perfeito funcionamento do órgão e não, apenas sua morfologia. Além de oferecer a incomparável vantagem de ser uma técnica não invasiva.

O radiofármaco é produzido a partir de elementos radioativos de meiasvidas curtas, pois a presença do elemento no organismo não pode ser duradoura, para não ocasionar danos maiores que os benefícios - Princípio da Justificação em radioproteção - ao paciente.

3. http://ipn0001.iridium.com.br 
Exemplos desses elementos, órgãos de utilização e meias-vidas são: Tc-99m (cérebro, glândulas salivares, fígado, pulmão, rins, sistema linfático, ossos e estômago) de meia-vida de 6 horas, I-131 (tireóide, pulmão e rins) de meia-vida de 8 dias, I-123 (tireóide e rins) de meia-vida de 13,2 horas, Ir-192 (garganta) de meia-vida de 75 dias, TI-201 (coração) de meia-vida de 3 dias, Cr-51 (intestino e rins) de meia-vida de 27,7 dias, Ga-67 (tecidos moles) de meiavida de 3 dias, dentre outros.

\subsubsection{COBALTO $60^{4}$}

O Co-60, um radioisótopo, é usado como fonte de radiação gama em radioterapia, esterilização de alimentos (esterilização fria) e radiografía indústrial para o controle de qualidade de metais, gamagrafia, (detecção de fendas).

É um radionuclídeo artificial produzido a partir da irradiação do Co-59 (encontrado na natureza) em um feixe de nêutrons. Como núcleo instável, ele se desintegra pela emissão de partículas $\beta^{-}$(elétrons) se transformando no elemento níquel-60, que, por sua vez, emitirá a radiação gama, para alcançar a estabilidade.

O Co-60 apresenta duas formas de decaimento para o isótopo estável de níquel $\mathrm{Ni}-60$. Em ambos os casos, 0 isótopo de cobalto Co-60 primeiramente decai, por emissão de uma particula $\beta^{-}$e de um antineutrino $(\bar{v})$, a um estado excitado do isótopo de niquel $\mathrm{Ni}-60$. Este processo pode ser representado pela reação

$$
{ }_{27} \mathrm{CO}^{60} \rightarrow{ }_{28} \mathrm{Ni}^{60 *}+\mathrm{e}^{-}+\overline{\bar{v}}
$$

onde $O$ asterisco indica que o isótopo de níquel é produzido em seu estado excitado ( $A$ energia disponivel na reação pode ser dividida entre o elétron e 0 antineutrino e desta forma o elétron pode emergir com energia cinética entre zero o um valor máximo). Na forma de decaimento mais provável $(99,85 \%)$ este estado

4. http://www.epa.gov/radiation/radionuclides/cobalt.htm\#properties 
excitado (do isótopo de níquel ${ }_{28} \mathrm{Ni}^{60}$ ) encontra-se energeticamente $2,405 \mathrm{MeV}$ acima do estado fundamental. Subseqüentemente o isótopo de níquel decai deste estado excitado ao estado fundamental, passando por um outro estado excitado 1,332 MeV acima deste e a com a emissão sucessiva de dois raios gama com energias bem definidas (1,173 MeV e 1,322 MeV). Na segunda forma de decaimento $(0,15 \%)$, o isótopo de cobalto ${ }_{27} \mathrm{Co}^{60}$ decai diretamente para o estado excitado 1,332 MeV acima do estado fundamental. A meia-vida do núcleo de cobalto é de 5,26 anos e estes processos de decaimento fornecem uma fonte de raios gama com um período de vida razoavelmente longo. O esquema de decaimento do Co-60 é apresentado na figura 1:

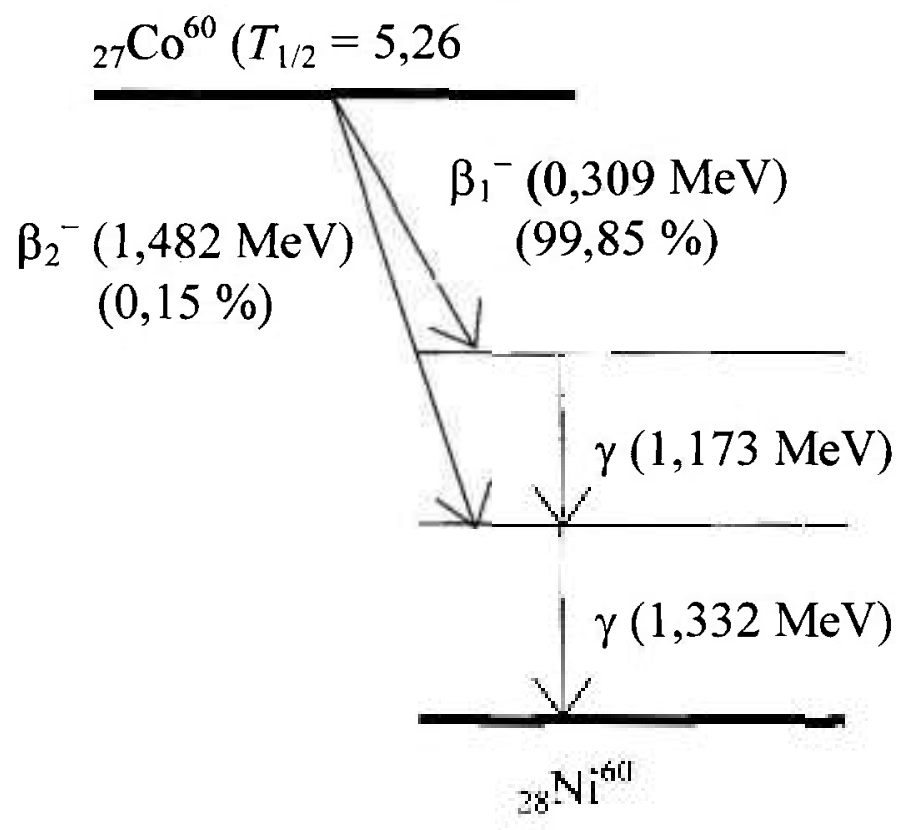

Figura 1 Esquema de decaimento do Co-60.

\subsubsection{DOSIMETROS UTILIZADOS NA RADIOTERAPIA}

Os dosimetros mais comumente utilizados são os tipo TLD. São posicionados no interior de simuladores antropomórficos, irradiados e, após, obtidas as leituras, dosímetro a dosímetro através de uma leitora termoluminescente.

São também utilizados os dosímetros de Alanina, em forma de pó, para a determinação das curvas de isodose por um equipamento de teleterapia (Chen et al, 2005) O método de leitura dos dosímetros é o RPE - Ressonância Paramagnética Eletrônica. 
Como padrão primário, pode-se utilizar o dosímetro de Fricke convencional ou, o Fricke gel. Os dosimetros de Fricke serão comentados no item 4.6.

Propõem-se, através do presente trabalho, dentre outros, a utilização de um Gel Dosimétrico a base de DL-Alanina e ĺon Ferroso cujo princípio é bastante semelhante ao Fricke Gel diferindo, contudo, pelo fato da presença do aminoácido DL-Alanina que propicia a oxidação do íon ferroso em íon férrico possibilitando a diferenciação entre diferentes doses.

Também são utilizados na radioterapia os Filmes Radiocrômicos e as Câmaras de lonização.

\subsubsection{DOSÍMETRO FRICKE E FRICKE GEL}

O dosímetro de Fricke consiste em uma solução aquosa, ácida, com íns ferrosos que após a irradiação, oxidam-se em íons férricos. Possue a vantagem de, diferentemente das câmaras de ionização e dos TLDs, ser equivalente ao tecido e possível de ser feito em pequenos volumes, da ordem de $1 \mathrm{~mL}$.

O dosímetro Fricke Gel ou Fricke modificado, FXG, difere do convencional pois é em forma de gel, através do emprego de gelatina de origem animal. Apresenta linearidade da resposta no intervalo de doses até $30 \mathrm{~Gy}$, tecido-equivalente, sendo portanto adequado ao uso que se propõe em metrologia em radioterapia.

\subsubsection{Imagem por Ressonância Magnética- IRM}

IRM - Imagem por Ressonância Magnética - também conhecida por Tomografia por Ressonância Magnética, TRM, é uma técnica diagnóstica, in vivo, não invasiva, não radioativa - sem o uso de radioisótopos ou de feixes da radiação - que fornece imagens do interior de um volume que se deseja examinar. 
Seu princípio de funcionamento é a variação no tempo de relaxação do spin do próton dos átomos de hidrogênio presentes na água que compõe, aproximadamente, $70 \%$ em massa os seres vivos.

A técnica consiste da medição do tempo de retorno desde a perturbação provocada por um pulso de rádio-freqüência, gerado no equipamento de Ressonância Magnética como perturbação ao equilibrio inicial dos spins, até sua posição de equilibrio, paralela ao campo magnético intenso produzido pela bobina supercondutora do equipamento.

No caso da dosimetria utilizando-se desta técnica, o que se deseja é a determinação desses tempos de retorno pois variam em função da dose de radiação aplicada ao dosímetro (Chu, 2001).

Os matérias na forma de gel, que contém Fe-ll em sua composição e, que após a irradiação são oxidados, aumentando a concentração de Fe-III, são empregados em dosímetros cuja leitura é feita pela técnica de Imagem por Ressonância Magnética - IRM - pois a presença íons férricos, Fe-III, diminui o tempo de relaxação do spin do próton do Hidrogênio presente nas moléculas de água. O que torna possivel sua diferenciação via variação do tempo de relaxação do spin da água e sua, subseqüente, aplicabilidade na determinação da dose absorvida. 


\section{4 - MATERIAIS E MÉTODOS}

\subsection{Gel Dosimétrico}

\subsubsection{DL-Alanina}

Foi utilizado o aminoácido DL-Alanina $\left[\mathrm{C}_{3} \mathrm{H}_{7} \mathrm{NO}_{2}\right.$ ], de peso molecular $89,09 \mathrm{~g} / \mathrm{mol}$, na forma de pó. A Alanina foi diluida na solução ácida e, por isso, não foi tomada nenhuma precaução no sentido de controlar a o tamanho dos grãos. Foi utilizada a DL-Alanina de alta pureza de fabricação dos laboratórios MERCK.

\subsubsection{Sulfato Ferroso Amoniacal}

Foi utilizado Sulfato Ferroso Amoniacal [ $\mathrm{Fe}\left(\mathrm{NH}_{4}\right)_{2}\left(\mathrm{SO}_{4}\right)_{2} 6 \mathrm{H} 2 \mathrm{O}$ ], (Sal de Mohr), de peso molecular 392,16 $\mathrm{g} / \mathrm{mol}$, em forma de grãos de tamanho variável, altamente sujeitos à umidade e de cor verde-azulada. Quando dissolvido em solução ácida contendo alanina, é estabelecido um equilibrio entre a população original de Ferro II e a de Ferro III, derivada da oxidação que ocorre devido à presença da Alanina de Ferro II para Ferro III. O Sulfato Ferroso Amoniacal também é de fabricação dos laboratórios MERCK.

\subsubsection{Alaraniado de Xilenol}

Alaranjado de Xilenol [ $\mathrm{C}_{31} \mathrm{H}_{28} \mathrm{~N}_{2} \mathrm{Na}_{4} \mathrm{O}_{13} \mathrm{~S}$ ] é encontrado na forma de pó, altamente sujeito à umidade, de peso molecular $760,60 \mathrm{~g} / \mathrm{mol}$ e de fabricação dos laboratórios MERCK. Foi utilizado como indicador de cor para utilização a técnica de espectrofotometria de absorção.

\subsubsection{Gelatina Suína}

Gelatina Suína 270P BLOOM / 8 Mesh, tipo ácida, do fabricante Gelita South-America. Foi utilizado o lote LF21743P 05 e $N^{\circ}$ de controle 5-3702. Essa gelatina é de altíssima pureza e utilizada na confecção de cápsulas para medicamentos, degradável pelo $\mathrm{HCl}$ estomacal.

Segundo dados fornecidos pelo fabricante, sua composição aproximada é dada na tabela 1 : 
Tabela 1: Composiçăo aproximada da gelatina suína do fabricante Gelita South América.

\begin{tabular}{|l|l|}
\hline \multicolumn{1}{|c|}{ Físico Químico } & \multicolumn{1}{c|}{ Limites } \\
\hline Bloom 6,66\% & $260-280$ \\
\hline Viscosidade 6,66\% & $40-51 \mathrm{mPs}$ \\
\hline Umidade & $8,0-13.0$ \\
\hline Cinzas & $\leq 1,5 \%$ \\
\hline $\mathrm{PH}(6,67 \%)$ & $4,5-5,8$ \\
\hline Cromo & $\leq 2 \mathrm{ppm}$ \\
\hline Arsênico & $\leq 1 \mathrm{ppm}$ \\
\hline Nitrogênio & $\geq 15,0 \%$ \\
\hline SO2 AFNOR & $\leq 40 \mathrm{ppm}$ \\
\hline Peróxido de Hidrogênio & $\leq 10 \mathrm{ppm}$ \\
\hline Metais pesados & $\leq 20 \mathrm{ppm}$ \\
\hline Chumbo & $\leq 1,5 \mathrm{ppm}$ \\
\hline Granulometria & $8 \mathrm{Mesh}$ \\
\hline
\end{tabular}

\subsubsection{Gelatina Bovina}

Gelatina Bovina 240B BLOOM / 20 Mesh, tipo básica, do fabricante REBIĖRE. Esta gelatina é proveniente do lote de número 505311/3/2/1 e é utilizada comercialmente para fins de consumo humano.

Segundo dados fornecidos pelo fabricante, sua composição aproximada é dada na tabela 2 :

Tabela 2: Composição aproximada da gelatina bovina do fabricante Rebière.

\begin{tabular}{|l|c|}
\hline Aminoácidos & $\begin{array}{c}\text { Proporção } \\
\text { (\%) }\end{array}$ \\
\hline Alanina & 11,0 \\
\hline Arginina & 9,0 \\
\hline $\begin{array}{l}\text { Ácido } \\
\text { aspartico }\end{array}$ & 6,7 \\
\hline Cisteína & 0,0 \\
\hline Cistina & 0,1 \\
\hline $\begin{array}{l}\text { Ácido } \\
\text { Glutâmico }\end{array}$ & 11,4 \\
\hline Glicina & 27,0 \\
\hline Histidina & 0,8 \\
\hline Prolina & 16,0 \\
\hline Hidroxiprolina & 13,8 \\
\hline
\end{tabular}

\begin{tabular}{|l|c|}
\hline Aminoácidos & $\begin{array}{c}\text { Proporção } \\
(\%)\end{array}$ \\
\hline Isoleucina & 1,5 \\
\hline Leucina & 3,3 \\
\hline Lisina & 4,3 \\
\hline Metionina & 0,8 \\
\hline Fenilalanina & 2,4 \\
\hline Serina & 4,1 \\
\hline Treonina & 2,2 \\
\hline Triptofano & 0,0 \\
\hline Tirosina & 0,3 \\
\hline
\end{tabular}


Embora as composições fornecidas por cada fabricante não atendam a um mesmo padrão, de formas a possibilitar uma análise comparativa entre as contribuições do tipo bovina e do tipo suína, fornecem diversas informações úteis. Como exemplo, níveis de alguns aminoácidos capazes de interagir com o $\mathrm{Fe}-\mathrm{ll}$ do gel.

\subsubsection{Agar-Agar}

Gelatina extraída de algas marinhas. Proveniente do distribuidor: KYODAI Com. de Produtos Alimentícios Ltda.

\subsection{7 Áqua Tri-Destilada}

Foi utilizada água tri-destilada na lavagem de toda a vidraria e no preparo do Gel Dosimétrico.

\subsection{7 Ácido Sulfúrico}

Foi utilizado ácido sulfúrico P.A. tanto no preparo das amostras dosimétricas quanto na solução para limpeza da vidraria. O ácido sulfúrico também foi obtido dos laboratórios MERCK.

\subsection{SIMULADOR DE GEL}

Para a confecção do simulador de pescoço (cilíndrico) utilizou-se gelatina bovina tipo 240B, tipo básica, dissolvida em água filtrada comum. Como molde, foi utilizado PMMA (polimetilmetacrilato) transparente como parede lateral e, como fundo, uma placa de petri. O cuidado na escolha do material plástico é justificado pelo fato de as irradiações serem feitas no simulador dentro do suporte plástico, apesar de poder ser feita sem o mesmo, visto que o gel apresenta consistência e resistência à temperatura ambiente. O PMMA apresenta comportamento semelhante à água e ao tecido para efeitos da interação da radiação gama do Co-60. 


\subsection{Cuidados com a vidraria}

Toda a vidraria utilizada foi lavada com solução de ácido sulfúrico e ácido nítrico na proporção de 1:1, à temperatura ambiente, durante 24 horas. 0 enxágüe foi feito com água tri-destilada em abundância e deixada a vidraria imersa por mais 24 horas. A secagem foi feita em estufa de esterilização.

\subsection{Equipamentos utilizados}

i) Espectrofotômetro de Absorção Óptica

Modelo: Shimadzu UV 2101PC

Certificado de calibração: $110203300078 \mathrm{KL}$

ii) Balança de precisão

Modelo: Mettler Toledo - AB204-S

Precisão: 0,0001 grama

Certificado de calibração: $1.040 .407-7$

\section{5 - MÉTODOS}

\subsection{1 - Cubetas}

Foram utilizadas cubetas de acrilico de alta qualidade com as quatro faces transparentes e de seção transversal quadrada, de arestas de $1 \mathrm{~cm}$ e altura de $5 \mathrm{~cm}$.

\subsection{2 - Preparação do gel}

\subsubsection{Gelelatinas Bovina e Suína}

Foram realizados ensaios com diferentes tipos de gelatinas. Gelatina bovina, suina e agar-agar.

Foram tomados alguns cuidados indispensáveis no preparo do $\mathrm{Gel}$ Dosimétrico. São apresentadas na seqüência as etapas que foram seguidas em sua formulação. 
Inicialmente, após terem sido separadas as massas de cada reagente, estes foram misturados à solução ácida de $\mathrm{H}_{2} \mathrm{SO}_{4}$. Em seguida, foi adicionada a gelatina a esta solução pré-aquecida a $50^{\circ} \mathrm{C}$ para a hidratação. Após 10 minutos, a temperatura foi elevada a $150^{\circ} \mathrm{C}$, sob constante agitação, para que a gelatina se dissolvesse. Atingindo a temperatura ambiente a solução era acondicionada nas cubetas de acrílico e levada para a refrigeração.

\subsubsection{Gelatina a base de alga marinha - Agar-Agar}

$\mathrm{Na}$ preparação das amostras utilizando-se o agar-agar, cuidados adicionais foram tomados. O agar-agar utilizado foi o de uso comercial na culinária. Primeiramente, o agar-agar não se apresenta como um bom agente solidificante à temperatura ambiente e em meio ácido, necessário para o favorecimento das reações de oxidação dos ions de ferro. Além do que, apresenta-se de maneira translúcida, não cristalina. Como seria utilizada a técnica de espectrofotometria de absorção para a determinação das doses, era de enorme importância que as amostras fossem o mais cristalinas, transparentes, possivel. Para que fosse possivel tornar o agar-agar cristalino o suficiente, consistente e em meio ácido procedeu-se as etapas:

i) Preparo do gel a base de agar-agar, meio ácido $-0,5 \mathrm{~N} \mathrm{em}$ $\mathrm{H}_{2} \mathrm{SO}_{4}$;

ii) Antes de sua solidificação, eram alojados no interior de tubos de ensaio com gelo e imediatamente levados a uma centrífuga;

iii) Eram deixados por 10 minutos em centrifugação e envoltos por gelo;

iv) A fase turva permanecia depositada no fundo da cubeta e o restante do volume tornava-se translúcido o suficiente para que se pudesse analisar por espectrofotometria. - Foram feitas 30 leituras de cada cubeta a fim de se reduzir estatisticamente as flutuações devidas à leve opacidade das amostas.

As amostras de dosímetros elaboradas com o agar-agar apresentavam baixa interferência do material solidificante, agar-agar, devido à sua pureza, mas apresentavam o inconveniente de necessitarem estar constantemente sob 
refrigeração e de não serem perfeitamente transparentes, obrigando a realização de um número grande de leituras (Mizuno, 2006).

\subsubsection{Intervalo entre a elaboração do gel, a irradiação e as leituras}

As amostras foram irradiadas sempre 24 horas após a preparação do Gel Dosimétrico e avaliadas por absorção óptica, em média, 1 hora após o término da irradiação no Centro de Tecnologia das Radiações - CTR/IPEN.

Como este $\mathrm{Gel}$ Dosimétrico está sendo feito em versão inédita, foram realizados todos os passos necessários à sua caracterização para o uso a que se propõe. Primeiramente, foram feitos os ensaios necessários para obter boa estabilidade do gel para estocagem à temperatura ambiente, como consistência, resistência à temperatura e homogeneidade, parâmetros visivelmente averiguáveis. Superada essa etapa, foi feita a caracterização dosimétrica propriamente dita, que consistiu na variação da concentração de cada reagente, de tal forma a obter a melhor resposta quando os dosímetros são irradiados com doses de controle, em geral $1 \mathrm{~Gy}$ e $2 \mathrm{~Gy}$ e não irradiados. Algumas vezes foram feitas irradiações com dose de 0,5 Gy. A justificativa foi encontrar a concentração ótima de cada componente do gel de tal forma a obter a melhor diferenciação entre as doses de 1 a 2 Gy, em condição de equilíbrio eletrônico, para a radiação gama do Co-60 no ar.

\subsubsection{Operação da Balança de Precisão}

$\mathrm{Na}$ balança utilizada, Metler Toledo AB204-S, com precisão até $0,0001 \mathrm{~g}$, era, primeiramente, medida a massa do recipiente onde seria colocado 0 reagente químico e, após isso, descontado - tara - o seu valor do valor total; reagente mais recipiente. Foi tomado o cuidado de garantir a precisão até 1 milésimo de grama, $0,001 \mathrm{~g}$.

\subsubsection{Operação do Espectrofotômetro Shimadzu 2101PC}

$\mathrm{Na}$ operação do Espectrofotômetro, foi utilizado o conjunto de dados que constam da seção 4.7, tabela 3. Neste equipamento, há duas cavidades e foi 
sempre utilizado uma cubeta na cavidade de leitura e nada na segunda cavidade, esta última, utilizada para se fazer o desconto da leitura da primeira.

Como existe um problema de estabilidade quanto à emissão das lâmpadas do Espectrofotômetro, foi sempre aguardado um intervalo de 30 minutos para que possíveis distorções nas leituras devidas à instabilidade transiente não afetassem os espectros obtidos.

\section{6 - ARRANJO EXPERIMENTAL PARA IRRADIAÇÃO}

$O$ arranjo experimental para a irradiação constou de um conjunto de 3 cubetas alojadas em uma capa de equilibrio eletrônico com paredes de $4 \mathrm{~mm}$ de espessura, confeccionada em acrílico, que é material tecido-equivalente para efeitos do comportamento da penetração da radiação gama do Co-60.

A figura 2 mostra o arranjo experimental utilizado. É possivel perceber o posicionamento a exatamente $20 \mathrm{~cm}$ da fonte, tipo Panorâmica, do conjunto de três dosimetros com a capa de equilíbrio eletrônico. 


\subsubsection{O irradiador}

- Fonte de Co-60, tipo panorâmica pertencente ao CTR - Centro de Tecnologia das Radiações, IPEN

- Energia média: $1,25 \mathrm{MeV}$

- Meia Vida: 5,27 anos

- Atividade (em 13/Nov./2006): 691,3 Ci (27,637 TBq )

- Taxa de Dose: $112,1 \mathrm{~Gy} / \mathrm{h}$

- Dose de Trânsito: 0,3352 Gy

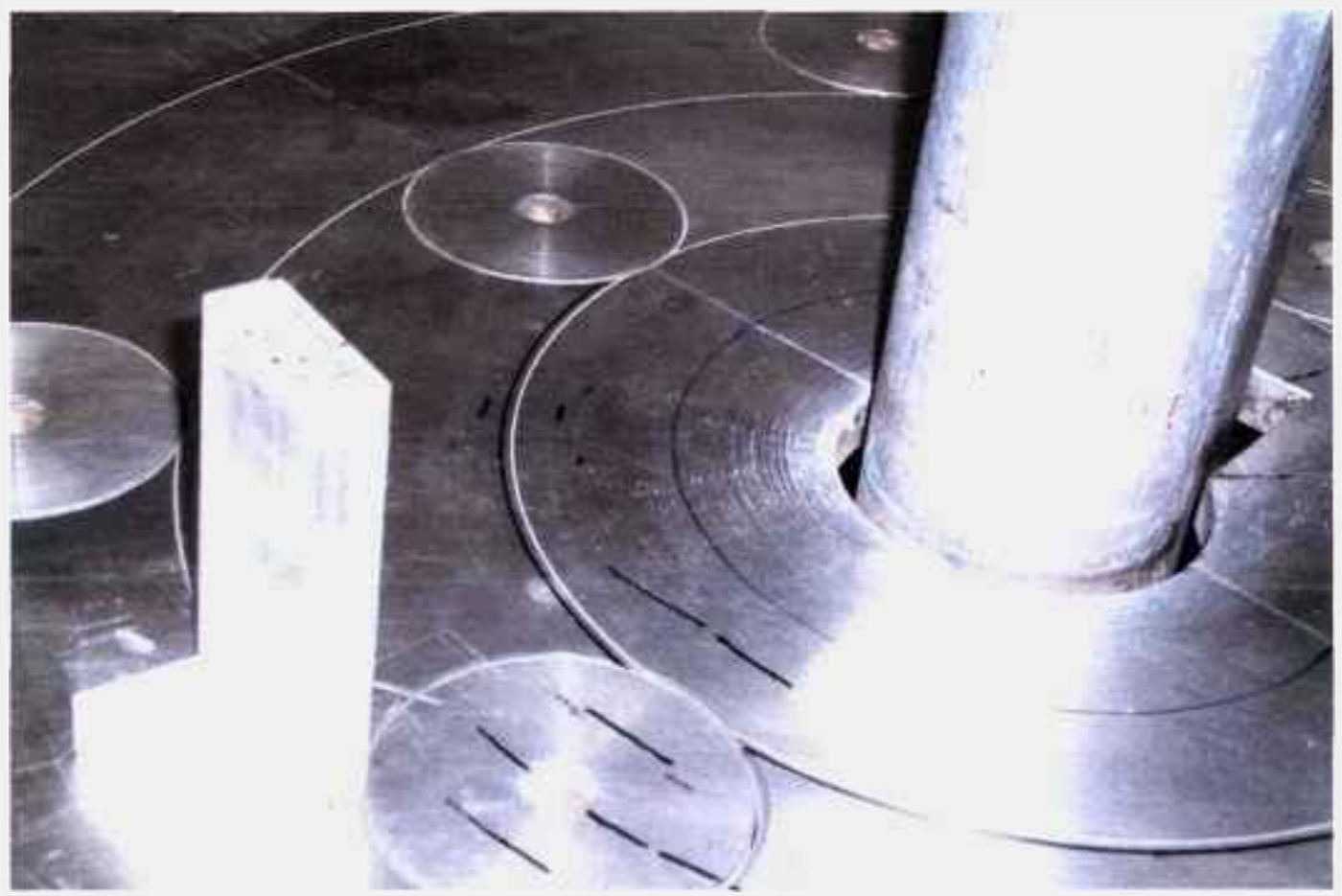

Figura 2. Arranjo experimental para a irradiação dos dosímetros de gel.

\subsection{MÉTODO ESPECTROFOTOMÉTRICO UTILIZANDO DL-ALANINA}

As leituras feitas no espectrofotômetro utilizaram as mesmas configurações do equipamento, as quais, constam na tabela 3 : 
Tabela 3. Ajuste dos parâmetros do espectrofotômetro utilizados nas medições.

\begin{tabular}{|l|lll|}
\hline \multicolumn{5}{|c|}{ Espectrofotômetro UV-2101PC } & UV-VS Shimadzu \\
\hline Measuring Mode & ABS (absorbância) & & \\
\hline Record Range & Low: 0.000 & High: & 6.000 \\
\hline Wavelenght Range & Start: 700 & End: & 400 \\
\hline Speed & FAST & & \\
\hline Slit Width & 5.0 & & \\
\hline Sampling Interval (nm) & AUTO & & \\
\hline
\end{tabular}

Foram feitos ensaios variando-se a velocidade das leituras (Speed) e variando-se a largura da fenda (Slit Width). Nas leituras variando-se os parâmetros Slit e Width nenhuma diferença no sinal foi observada nos espectros.

Foram realizadas diversas medidas das cubetas contendo o Gel Dosimétrico no intuito de encontrar qual a concentração ideal de cada componente. Utilizou-se, inicialmente, seguindo-se o trabalho de dissertação de Costa (1994).

\subsubsection{Uso do branco na segunda cubeta}

No espectrofotômetro UV-2101PC existem 2 cavidades. A primeira para a cubeta que se deseja analisar e a segunda para a cubeta que deve conter o material de referência a ser subtraído, descontado, das leituras.

Foram realizados ensaios onde, na segunda cubeta, foram colocados água, e, em outro ensaio, gelatina a base de água. $O$ objetivo foi estudar a contribuição da gelatina no resultado e verificar se oferecia muito ruído. Foi decidido pela não utilização de cubeta com qualquer material na segunda cavidade pelo fato de que, provavelmente devido aos meios serem bastante parecidos; cubetas 1 e 2 , resultava em um erro relativo da ordem de $30 \%$ maior, o que comprometia uma melhor avaliação das doses menores, visto que a diferença entre as respostas das cubetas com o material dosimétrico (cubeta 1) e a cubeta com a gelatina pura (cubeta 2) era menor quando era utilizada esta segunda cubeta com gelatina. 
Optou-se, portanto, pela utilização de uma cubeta de acrílico vazia na segunda cavidade.

\section{8- SISTEMA DE IRRADIAÇÃO}

As exposições à radiação gama foram efetuadas utilizando-se uma fonte de Co-60 tipo panorâmica pertencente ao CTR - Centro de Tecnologia das Radiações, do IPEN. Essa fonte, permite o posicionamento das amostras a diferentes distâncias, $(5,10,20,30,40,50$ e $60 \mathrm{~cm}$ a partir da frente ou de trás da fonte) proporcionando, assim, diferentes taxas de doses.

O nuclídeo radioativo Co-60 está na forma de um bastão (chamado de lápis), o qual é suspenso, a partir da blindagem que se localiza abaixo da mesa, até a porção superior da mesma. De forma que fique exposto no interior da peça metálica, conforme é mostrado na figura 3. O Co-60 é uma fonte selada com o máximo de segurança, de maneira a evitar contato direto com o material a ser irradiado.

O dispositivo de irradiação consiste de um sistema que faz com que a fonte seja retirada da blindagem, localizada abaixo do plano da mesa e seja suspensa até a altura onde serão realizadas as irradiações. Esse equipamento de irradiação está montado em uma sala blindada no sub-solo do CTR.

Para fixarmos uma taxa de dose de forma a manter uniformes as irradiações, foi fixada a distância fonte-amostra em $20 \mathrm{~cm}$, na parte de trás, conforme ilustra a figura 2 , já apresentada.

A imagem do aparato do irradiador é mostrado na figura 3:

As cubetas com o material dosimétrico possuem uma seção transversal quadrada de arestas de $1 \mathrm{~cm}$ e altura de $5 \mathrm{~cm}$. Foram irradiadas sempre a $20 \mathrm{~cm}$ da parte de trás da fonte utilizando-se uma capa de equilíbrio eletrônico de $4 \mathrm{~mm}$ de espessura. De tal forma a garantir a dose desejada exatamente no centro das cubetas. 


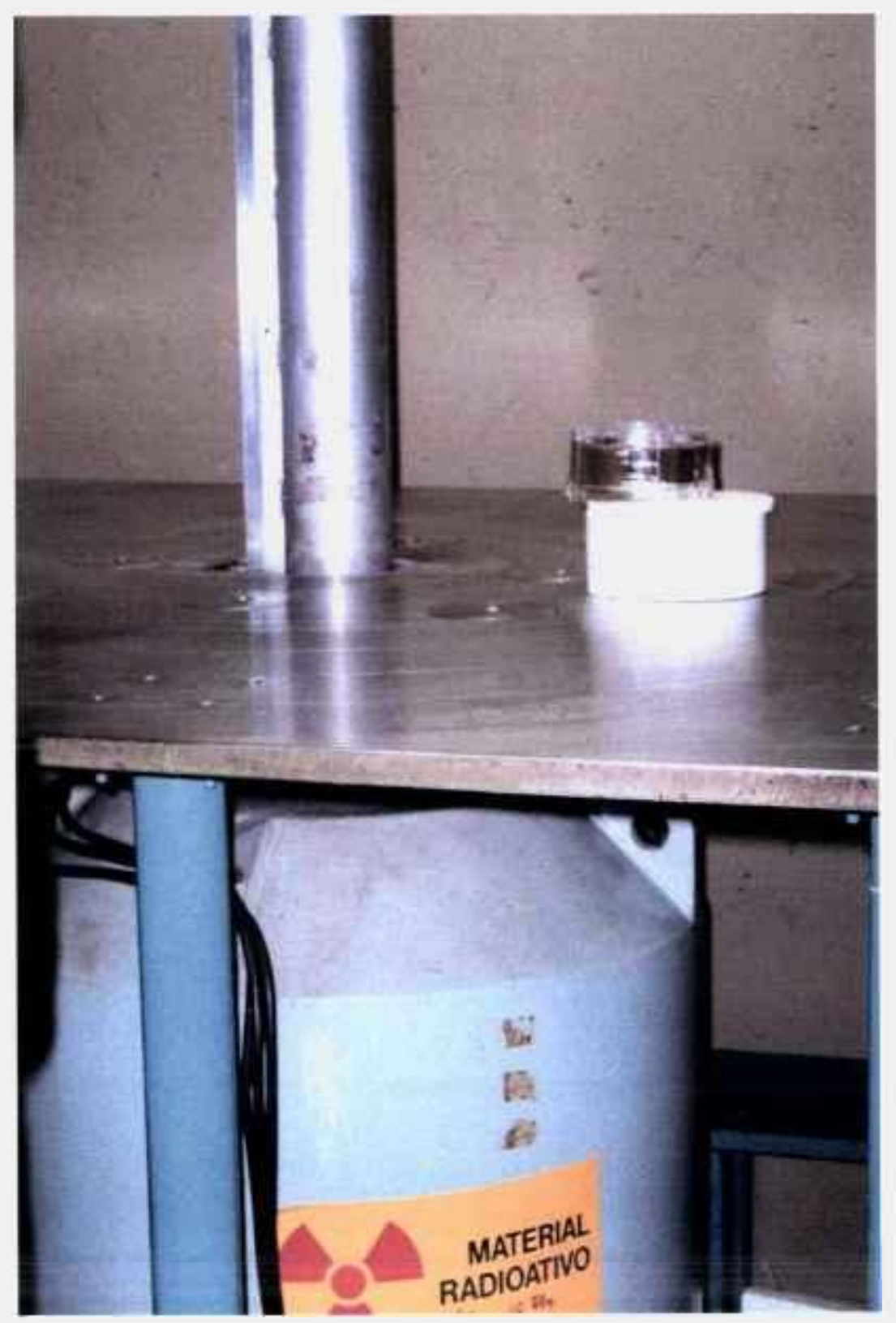

Figura 3. Fonte Panorâmica de Co-60. Pertencente ao CTR / IPEN Centro de Tecnologia das Radiações. 


\subsection{INTERPRETAÇÃO DOS RESULTADOS}

\subsubsection{Avaliação dos Dados}

A fim de padronizar o método, as cubetas irradiadas foram mantidas sob refrigeração, irradiadas à temperatura ambiente, visto que não era possivel um controle de temperatura devido às condições do aparato, e avaliadas, por espectrofotometria de absorção, também à temperatura ambiente, em, aproximadamente, 1 hora após terem sido irradiadas.

Nos casos em que foram realizadas leituras para avaliar o decaimento da resposta em função do tempo de armazenamento, foram realizadas leituras em intervalos não uniformes de tempo. Em geral, as leituras foram feitas em intervalos de 1, 2 ou 3 dias.

O tempo aproximado para a leitura de cada cubeta com material dosimétrico foi de 3 minutos, à temperatura ambiente.

Todas as leituras foram realizadas à temperatura ambiente, principalmente devido ao fato de as cubetas, ao serem retiradas da refrigeração, apresentarem em suas paredes gotículas de água que comprometem as leituras. Esse fato obrigou que sempre fosse esperado o tempo de 1 hora após a retirada das cubetas da refrigeração a fim de que cessasse a condensação e, subseqüente, formação de gotículas de água e, ainda, devido ao fato de a leitura do Gel Dosimétrico apresentar menos ruído à temperatura ambiente.

\subsubsection{Tratamento dos Dados}

Os pontos apresentados nas curvas representam o valor médio obtido para 3 amostras diferentes, com 4 leituras de cada uma, uma para cada face das cubetas, onde o desvio padrão da médio é indicado pelas barras de incerteza. 


\section{RESULTADOS E DISCUSSÕES}

\section{1- MÉTODO ESPECTROFOMÉTRICO}

Foi verificado, para o primeiro ajuste de velocidade de leitura do espectrofotômetro, Speed, que em nada influenciava as curvas de absorbância quando eram utilizados os modos Fast, Médium ou Slow. Por isso, e por economia de tempo, visto as os métodos Medium e Slow são progressivamente mais demorados, foi utilizado o modo Fast.

Quanto à largura da fenda (Slit Width), foram realizadas medidas em todos os valores e verificado quem em nada era alterado o resultado. Por isso, foi fixado o valor do ajuste de fábrica do equipamente, qual seja, 5.0.

A proposta do presente trabalho é a obtenção de um Gel Dosimétrico a base de DL-Alanina e Ferro-II. Ao se acrescentar o aminoácido DL-Alanina à solução original de Costa (Costa, 1994) mais o agente solidificante gelatina, foram obtidas leituras onde o ruído era elevado e a diferença entre leituras de doses no intervalo de 1 a 20 Gy eram absolutamente indistinguíveis.

As leituras obtidas não permitiam diferenciar irradiações com doses variando de 2 a $20 \mathrm{~Gy}$. Somente era percebida leitura diferente para o dosimetro (cubeta) de controle que não era irradiada.

A curva dose-resposta fornecia informação absolutamente inútil, visto que as incertezas associadas eram maiores que as variações nas leituras.

O espectro de absorbância obtido é apresentado na figura 4 e a curva dose-resposta e respectivas barras de incertezas na figura 5. As incertezas nas medidas eram superiores aos valores das próprias medidas, ainda que calculadas sobre um número grande de pontos, superior a 30 . O que não era desejado. 


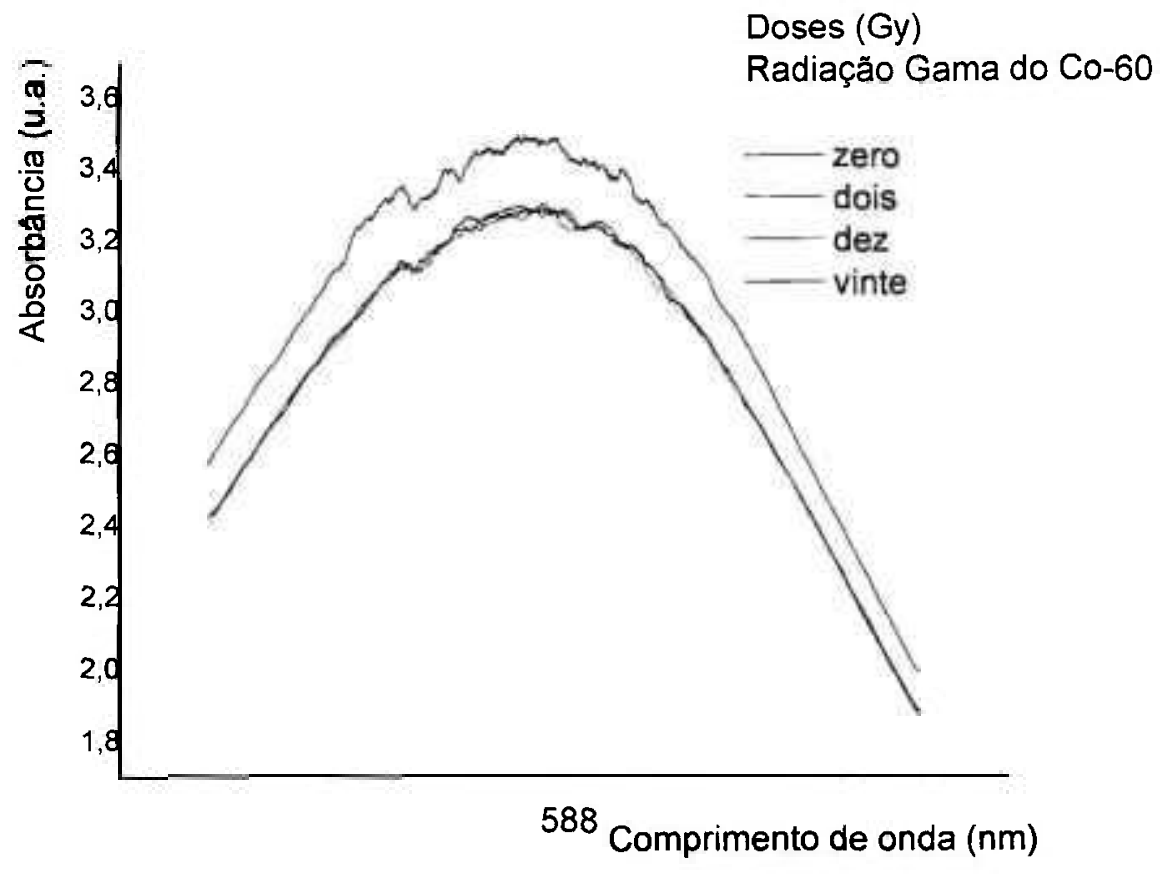

Figura 4. Espectro de absorção para a formulação original da solução dosimétrica de alanina.

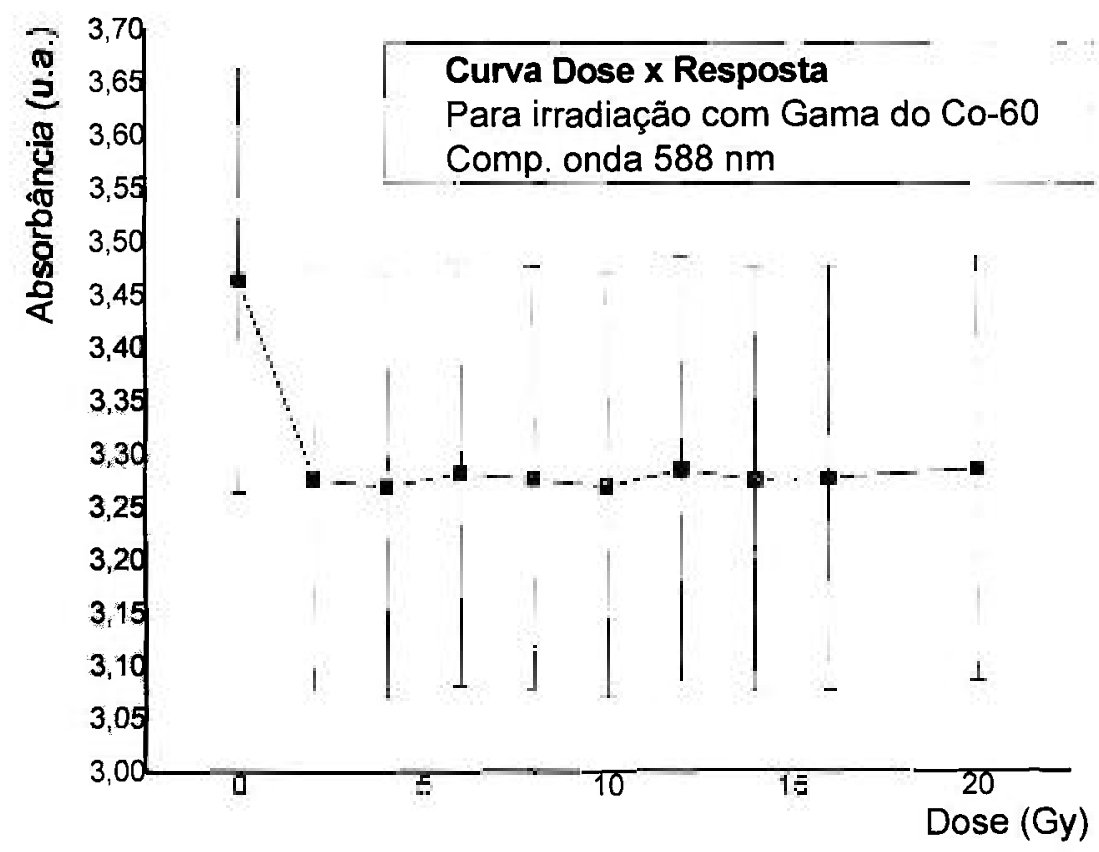

Figura 5. Dose-resposta para $\circ$ gel de alanina produzido a partir da formulação original, irradiado no ar, em condições de equilíbrio eletrônico. 
Esse comportamento é semelhante para as doses no intervalo de dose de 1 a $50 \mathrm{~Gy}$. A partir disto, procedeu-se aos ensaios variando-se reagente a reagente a fim de se obter uma concentração ótima de cada um desses a ponto de tornar nitida, distinguivel, as leituras de cubetas irradiadas com diferenças de 1 Gy de dose, ou menos ainda. Foram feitas leituras com diferença de até $0,5 \mathrm{~Gy}$, na formulação final.

Primeiramente, foi variado o tipo de gelatina a ser empregado. Foram usadas as gelatinas:

- Tipo Bovina - 240 Bloom - Tipo Básica

- Tipo Suína - 270 Bloom - Tipo Ácida

- Agar-agar

\subsection{ESTABILIDADE MECÂNICA DO GEL (CONSISTÊNCIA)}

\subsubsection{GELATINAS DE TIPO BÁSICA (BOVINA) E ÁCIDA (SUÍNA)}

Inicialmente, foram feitos ensaios com diferentes concentrações de gelatina bovina $240 \mathrm{~B}$, tipo básica, tentando obter a estabilidade do gel à temperatura ambiente e consistência adequada.

Em uma segunda etapa, foi utilizada gelatina suína 270P Bloom, tipo ácida, devido à sua maior consistência, e, principalmente, pelo fato de sua constituição interferir de forma muito menor do que a da gelatina bovina na absorção óptica do gel, conforme pode ser observado visualmente através da observação da variação da tonalidade do gel em ensaios realizados utilizando-se os tipos de gelatina básico e ácido, apresentados na figura $6 \mathrm{~A}$.

Nas imagens das figuras $6 \mathrm{~A}$ e $6 \mathrm{~B}$, são apresentados dois conjuntos de amostras. Sendo que o conjunto de baixo contém a gelatina suina, tipo ácida, e o de cima, contém a gelatina bovina, tipo básica. 


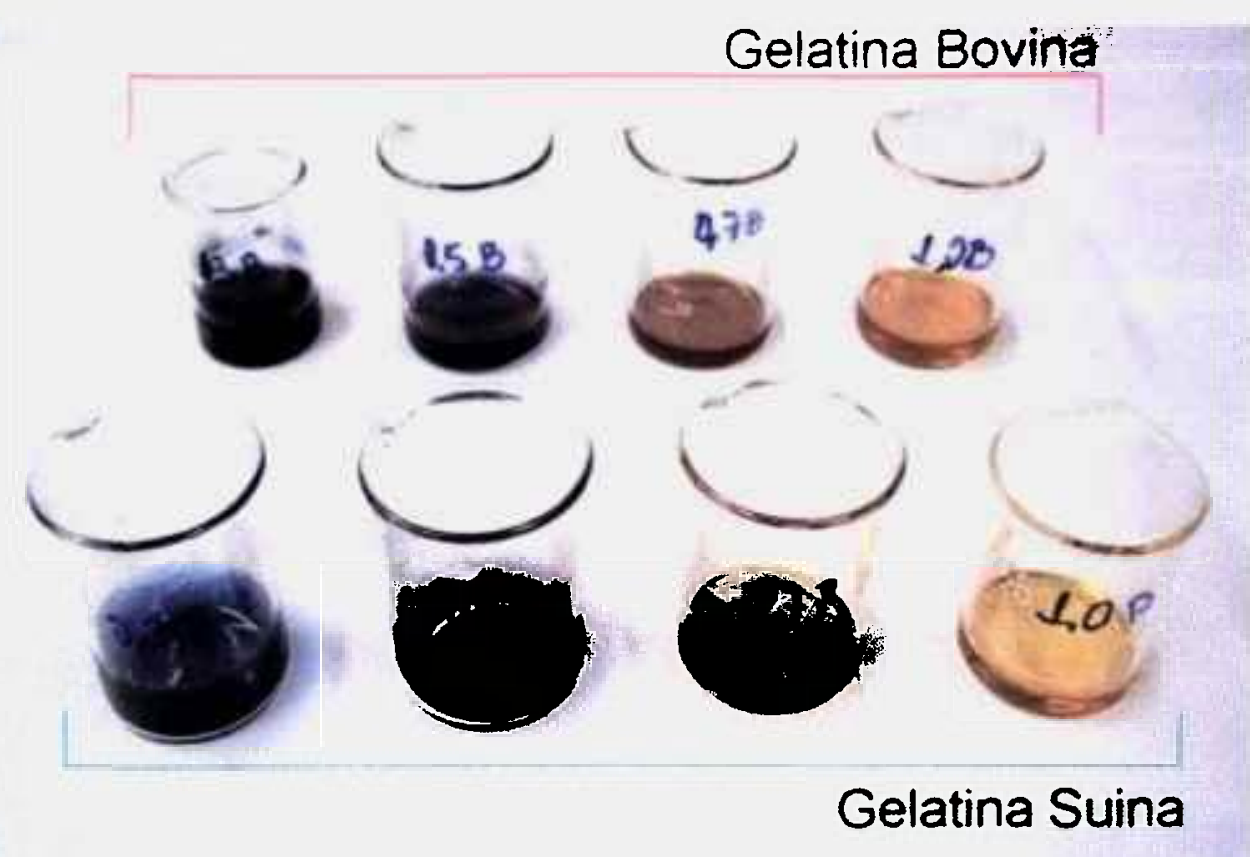

Figura 6A. Ensaio comparativo: amostras não irradiadas de gelatina suína e gelatina bovina em função da acidez da solução. A numeração marcada nos beckeres corresponde à concentração normal $(\mathrm{N})$ em ácido sulfúrico.
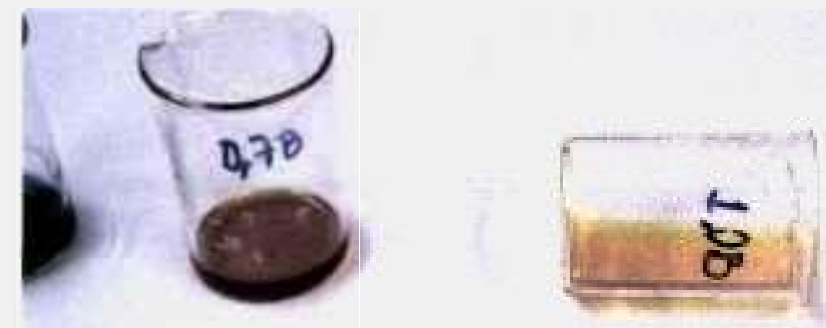

\section{Bovina}
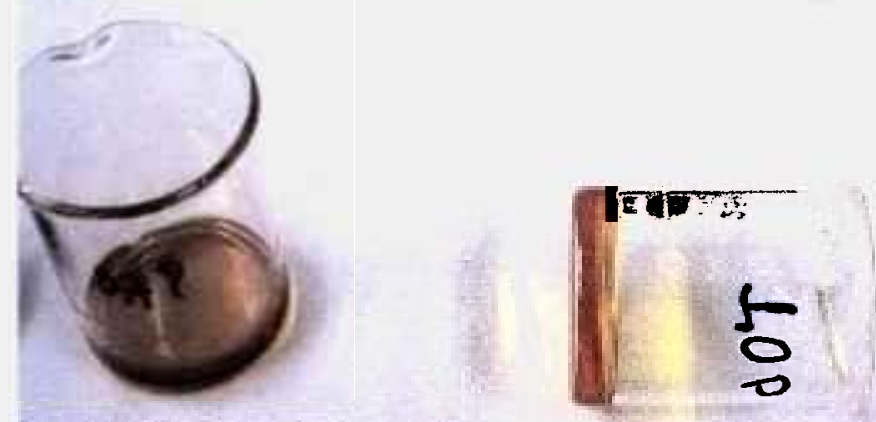

\section{Suina \\ (Consistente)}

Figura 6B. Gelatina tipo ácida, suína: mais resistente à acidez do que a tipo básica, bovina. A numeração marcada nos beckeres corresponde à concentração normal $(\mathrm{N})$ em ácido sulfúrico.

Como gelatinas são, em geral, pouco estáveis quando em meio ácido, esses ensaios objetivavam evidenciar, visualmente, o fato da gelatina suina $270 \mathrm{P}$, 
ácida, interferir em menor grau no escurecimento da solução, ou seja, na sua absorção óptica, do que a de tipo bovino, 240P, básica. Vide figuras 6A e 6B.

Pode ser observada, ainda, a maior resistência à acidez por parte da gelatina suina, visto que, na figura $6 \mathrm{~B}$, a gelatina tipo $P$ continua consistente, enquanto a tipo $\mathrm{B}$ já perdeu sua consistência à temperatura ambiente. A partir desta etapa, foi convencionada a utilização de uma concentração de $1 \mathrm{~g}$ para cada $10 \mathrm{~mL}$ de solução $0,5 \mathrm{~N}$ em ácido sulfúrico.

Devido ao fato de a gelatina do tipo ácida, suína, apresentar melhores características mecânicas, e interferir menos na oxidação do composto, optou-se por usá-la na fabricação do Gel Dosimétrico. De tal maneira que não foram realizados testes de absorvância comparativa entre os dois tipos de gelatina.

\subsubsection{Gelatina de Algas Marinhas - Agar-Agar}

Foram, também, realizados ensaios para o Agar-Agar. Os resultados obtidos, em termos de estabilidade mecânica, foram questionáveis. Visto que este agente solidificante não apresenta perfeita transparência, ver figura 7 , o que é condição essencial para a utilização na espectrofotometria de absorção, e, ainda, exigia condições de preparo demasiadamente controladas, tais como a exigência de centrifugação durante o processo de solidificação.

O grande problema encontrado é que, sendo feito desta forma, embora fosse razoavelmente transparente, a amostra, não se mantinha consistente à temperatura ambiente. Foi, contudo, apresentado um trabalho onde foi aplicado 0 Agar-Agar como agente de solidificação (Mizuno, 2006).

Figura 7. Ensaio com agar-agar pura em água destilada. - Ligeiramente turva. 


\subsection{DETERMINAÇÃO DO PH DA SOLUÇÃO}

A partir de dados catalogados (Perrin, 1979), foi utilizado um intervalo de $\mathrm{pH}$ tal que contivesse os intervalos de máxima concentração das duas espécies de Ferro em tela; o Fe-Il e o Fe-III. Optou-se por utilizar as concentrações normais: $0,1 \mathrm{~N} ; 0,3 \mathrm{~N} ; 0,5 \mathrm{~N} ; 0,7 \mathrm{~N} ; 1,0 \mathrm{~N} ; 1,5 \mathrm{~N}$ e $2,0 \mathrm{~N}$. Estes valores cobrem o intervalo de 3,0 a 0,3 para valores expressos em $\mathrm{pH}$.

Foram realizados ensaios com cada uma das concentrações normais contendo a gelatina em meio ácido. Por questão de padronização e uniformização dos procedimentos, primeiramente, foi adicionada a gelatina às soluções, esperou-se 10 minutos para que esta fosse hidratada e, em seguida, a solução foi aquecida de forma branda e gradual até a temperatura de $150^{\circ} \mathrm{C}$, na qual a gelatina se dissolve por completo.

Tendo em vista a instabilidade das gelatinas quando em meio ácido, primeiramente, foi observado quais concentrações manteriam a consistência do gel quando, depois de prontas e retiradas da refrigeração, as amostras fossem deixadas à temperatura ambiente. Foram obtidos os resultados apresentados na tabela 4.

Tabela 4. Consistência em função da concentração normal de ácido sulfúrico.

\begin{tabular}{|c|c|c|}
\hline $\begin{array}{c}\text { Concentração (N) } \\
\mathbf{H}_{\mathbf{2}} \mathbf{S O}_{\mathbf{4}}\end{array}$ & $\mathbf{p H}$ (medido) & Resultado \\
\hline 0,1 & 3,0 & Consistente \\
\hline 0,3 & 1,7 & Consistente \\
\hline 0,5 & 1,5 & Consistente \\
\hline 0,7 & 1,3 & NÃO Consistente \\
\hline 1,0 & 1,0 & NÃO Consistente \\
\hline 1,5 & 0,5 & NÃO Consistente \\
\hline 2,0 & 0,3 & NÃO Consistente \\
\hline
\end{tabular}

Em seguida, terminada a fase de ensaios quanto à consistência e resistência à temperatura ambiente, foram feitas as análises de cada uma dessas soluções empregando a técnica de espectrofotometria de absorção num espectrofotômetro Shimadzu, UV-2101PC, no intervalo de comprimentos de onda de 400 a $700 \mathrm{~nm}$. 
Foram utilizadas as seguintes concentrações dos reagentes.

Sulfato Ferroso Amoniacal (sal de Mohr): $0,2 \mathrm{mM}$ Alaranjado de Xilenol: $\quad 0,2 \mathrm{mM}$

DL Alanina: $\quad 1 \mathrm{~g} / 50 \mathrm{~mL}$ de solução

Gelatina 270P: $\quad 5 \mathrm{~g} / 50 \mathrm{~mL}$ de solução

As concentrações de SFA (sal de Mohr) e de Alaranjado de Xilenol, baseiam-se no trabalho de Costa (1994).

Em todas as medidas foi utilizado o comprimento de onda de $588 \mathrm{~nm}$. Visto que existe um máximo de absorção neste valor para o $\mathrm{Fe}$-III formado quando da composição do gel, e acentuado devido à irradiação. Quanto à concentração de DL Alanina, esta foi determinada variando-se de 1 em 1 grama a sua massa e analisados os espectros. As amostras não irradiadas e irradiadas com doses de 0,1 e 2 Gy foram avaliadas, procurou-se obter a maior distinção entre doses de 1 e $2 \mathrm{~Gy}$. Os resultados obtidos são apresentados na figura 8:

Pode ser observado que na concentração de $0,5 \mathrm{~N}$ em ácido sulfúrico, existe uma maior diferença nos valores de absorvância entre as doses de 1 e 2 Gy. Além disso, nesta concentração ácida, a gelatina tipo $P$, suína, mantém perfeitamente sua consistência mesmo não estando sob refrigeração.

Desta forma, foi fixada a concentração em ácido sulfúrico em $0,5 \mathrm{~N}$, o que corresponde a um $\mathrm{pH}$ de 1,5 que, por sua vez, encontra-se perfeitamente entre os dois máximos das concentrações de Fe-II e Fe-III conforme valores tabelados (Perrin, 1979).

Foi escolhido este valor por tratar-se de um valor de $\mathrm{pH}$ em uma região de equilíbrio entre duas espécies; o Fe-II e Fe-III, pois, durante a preparação do dosimetro, existe, inicialmente, uma dada concentração de Fe-II, maior do que a de Fe-III. Após a irradiação, há a oxidação do Fe-II em Fe-III, que faz com que as espécies variem proporcionalmente. Daí a importância da escolha de uma concentração em ácido tal que o dosímetro encontre-se entre esses máximos. 


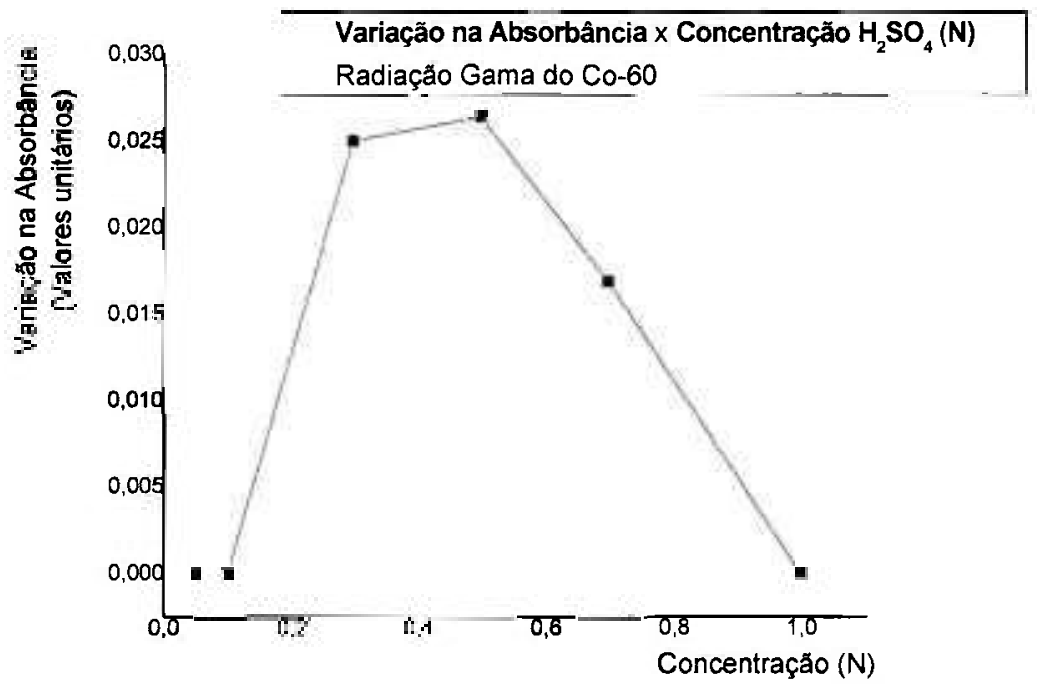

Figura 8 Diferença entre o sinal de A.O. de amostras do gel irradiadas com doses de 1 e 2 Gy em função da concentração Normal em $\mathrm{H}_{2} \mathrm{SO}_{4}$ do gel.

\subsection{DETERMINAÇÃO DA CONCENTRAÇÃO DO SULFATO FERROSO AMONIACAL (SAL DE MOHR)}

De posse das concentrações de Gelatina suína, $1 \mathrm{~g} / 10 \mathrm{~mL}$ de solução, e da concentração ácida, $0,5 \mathrm{~N} \mathrm{em} \mathrm{H}_{2} \mathrm{SO}_{4}$, foi determinada a concentração ótima de Sal de Mohr. Para tal, foi variada a concentração deste reagente mantendo-se constante a concentração dos demais reagentes, na proporção:
Alaranjado de Xilenol: $\quad 0,2 \mathrm{mM}$
DL Alanina:
$1 \mathrm{~g} / 50 \mathrm{~mL}$ de solução
Gelatina 270P:
$5 \mathrm{~g} / 50 \mathrm{~mL}$ de solução
Concentração $\left(\mathrm{H}_{2} \mathrm{SO}_{4}\right): 0,5 \mathrm{~N}$

Os espectros de absorção das diferentes soluções são apresentados na figura 9.

Para esta etapa foram avaliadas amostras não irradiadas e aplicadas doses de 1 e 2 Gy em cinco dosimetros, a fim de se determinar qual a concentração de Fe-ll que forneceria a melhor diferenciação entre as doses aplicadas. Vale observar que o conjunto de 3 curvas correspondentes à concentração de $1,5 \mathrm{mM}$ apresenta maior diferenciação entre as doses de 
1 e 2 Gy, que é o desejado. O resultado deste ensaio para diferentes concentrações de Fe-ll é apresentado na figura 10.

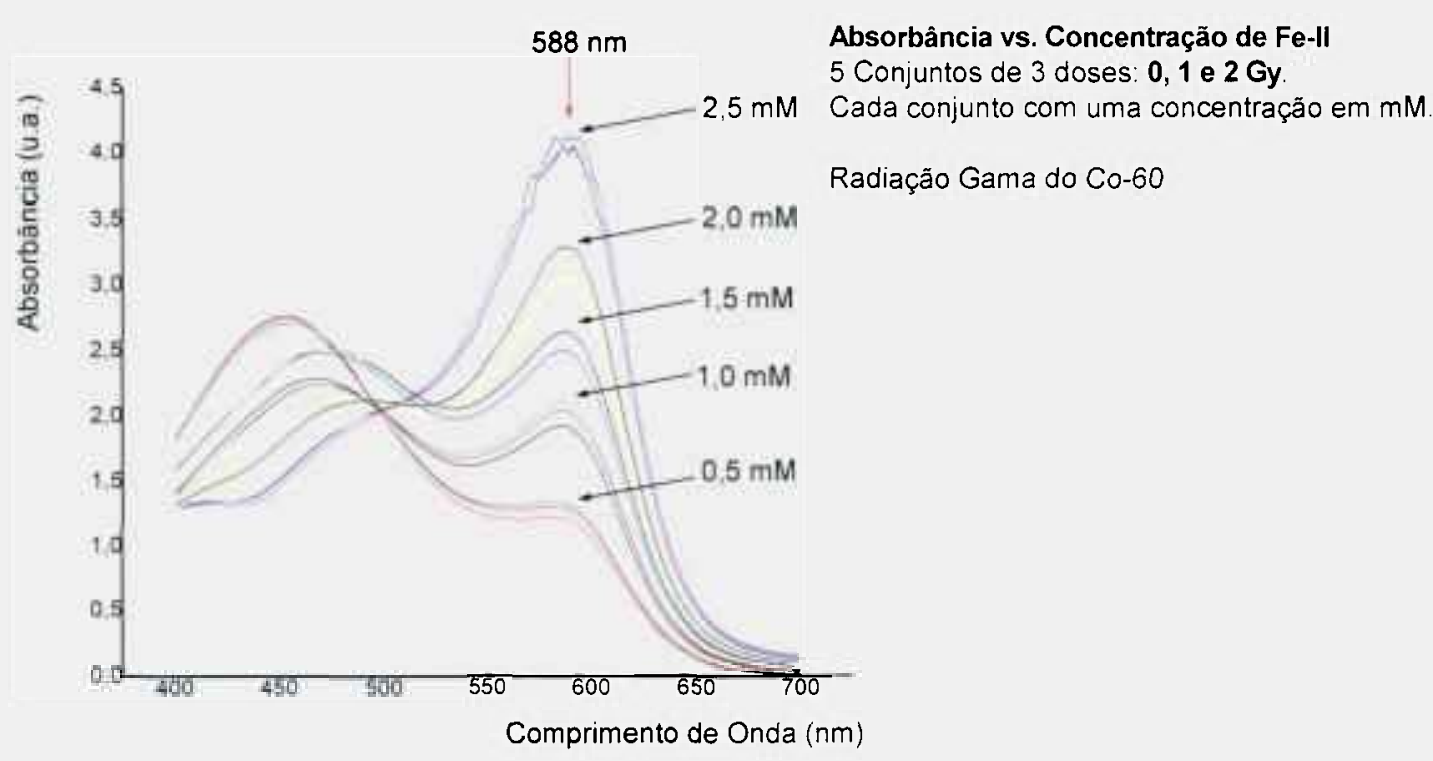

Figura 9 Espectro de absorção de amostras de gel em função do comprimento de onda $(\mathrm{nm})$ para diferentes concentrações $(\mathrm{mM})$ de Fe-II.

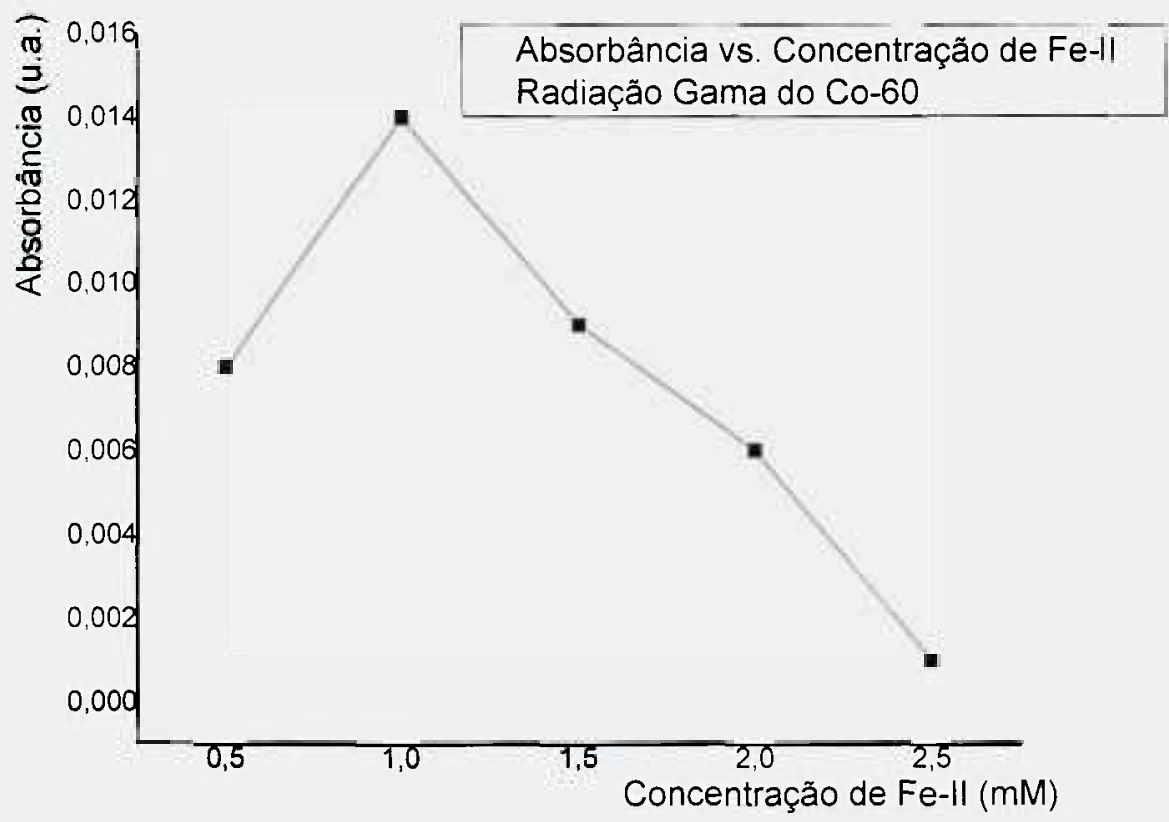

Figura 10 Diferença entre as medidas de absorbância do gel para doses de 1 e 2 Gy em função da concentração de Fe-II. 
A figura 10 mostra que ocorre um aumento na diferença dos valores de absorvância entre as doses de 1 e 2 Gy quando se utiliza uma concentração próxima a 1,0 mM de Sulfato Ferroso Amoniacal, Fe-II.

\title{
5.5 DETERMINAÇÃO DA CONCENTRAÇÃO DE DL-ALANINA
}

A partir da fixação das concentrações dos outros reagentes, foi determinada a concentração ótima de DL-Alanina. Foram utilizados os seguintes reagentes, nas respectivas proporçōes:

\author{
Alaranjado de Xilenol: $0,2 \mathrm{mM}$ \\ Gelatina 270P: $5 \mathrm{~g} / 50 \mathrm{~mL}$ de solução \\ Concentração $\left(\mathrm{H}_{2} \mathrm{SO}_{4}\right): 0,5 \mathrm{~N}$ \\ Sulfato Ferroso Amoniacal: $1,0 \mathrm{mM}$
}

Os resultados de absorvância obtidos são apresentados na figura 11 Pode ser observado que após a quantidade de 5 gramas de alanina, a diferença torna-se constante.

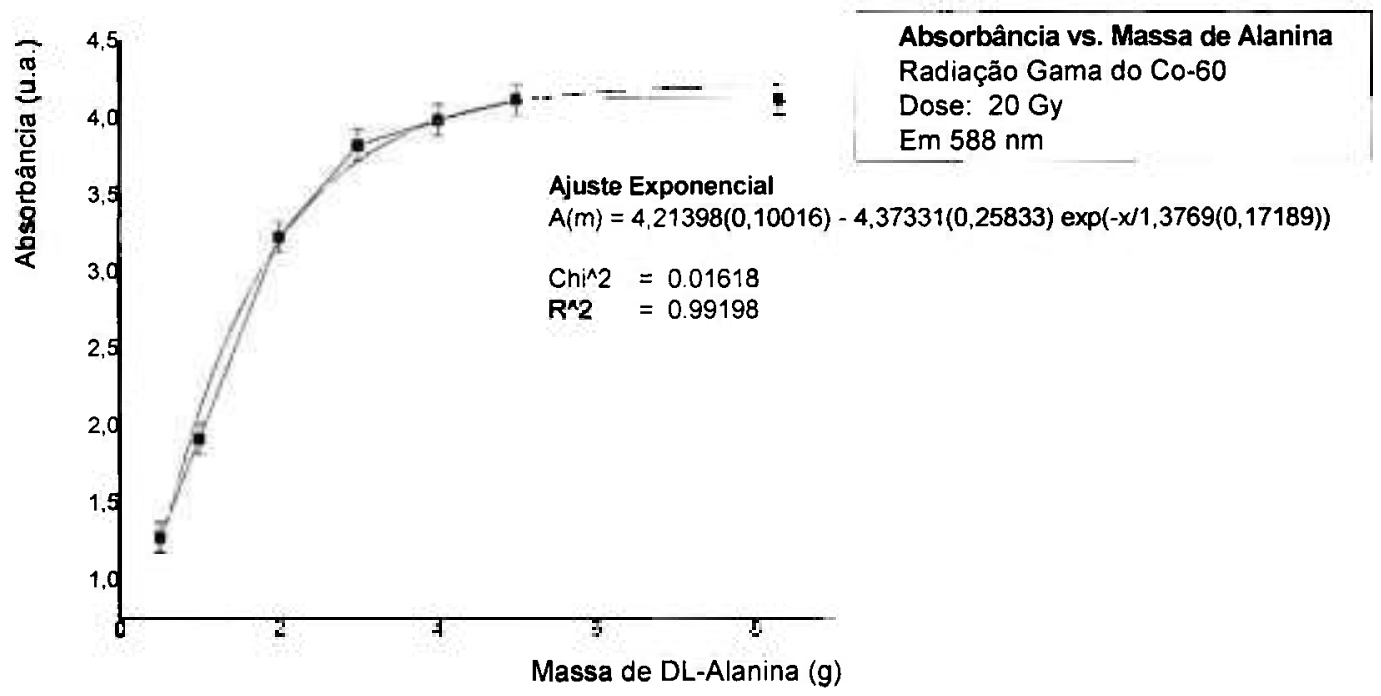

Figura 11 Diferenças na absorvância da solução gel em função da dose de 1 e 2 Gy para diferentes massas de DL-Alanina.

Com esta última etapa foi encerrada a fase de caracterização do material dosimétrico, passando-se à fase de testes, realizando-se irradiações com diferentes doses, taxas de dose, estudo do decaimento do sinal em função do 
tempo (em dias) e, posterior utilização deste Gel Dosimétrico em medidas realizados com irradiação em um simulador.

\subsection{DETERMINAÇÃO DA CONCENTRAÇÃO DE ALARANJADO DE XILENOL}

Foi utilizada a mesma concentração indicada na dissertação de mestrado de Costa (1994), que é de 0,2 mM de Alaranjado de Xilenol, sem maiores preocupações, pois a influência deste reagente na solução é secundária, visto que, o que se pretende em trabalhos futuros, é o emprego deste gel em técnicas de dosimetria independentes da formação de centros de cor. Por isso, e pelo fato do comportamento regular deste componente já ser bem conhecido (Gray et al, 1999; Perrin, 1979), preferiu-se utilizar o valor constante do referido trabalho; $0,2 \mathrm{mM}$.

Portanto, o Gel Dosimétrico caracterizado é constituido das seguintes concentraçōes:

Sulfato Ferroso Amoniacal: $1,0 \mathrm{mM}$
Alaranjado de Xilenol: $\quad 0,2 \mathrm{mM}$
DL-Alanina:
$3,0 \mathrm{~g} / 50 \mathrm{~mL}$ de solução
Gelatina 270P:
$5,0 \mathrm{~g} / 50 \mathrm{~mL}$ de solução
Concentração $\left(\mathrm{H}_{2} \mathrm{SO}_{4}\right): 0,5 \mathrm{~N}$

\subsection{ENSAIO COMPARATIVO SEM DL-ALANINA}

Este Gel Dosimétrico que inova em sua formulação em relação ao já conhecido dosímetro tipo Fricke, pelo fato de possuir em sua formulação o aminoácido DL-Alanina em meio gelatinoso. Foi feito, a título de comparação, um ensaio com a formulação obtida acima, SEM a adição do aminoácido, para estudo da contribuição da alanina à formação do complexo de Fe-III na solução, antes e após a irradiação. O gel foi preparado com os seguintes reagentes e respectivas concentrações:

Sulfato Ferroso Amoniacal: $1,0 \mathrm{mM}$

Alaranjado de Xilenol: $\quad 0,2 \mathrm{mM}$ 
DL-Alanina: NÃO COLOCADO

Gelatina 270P: $\quad 5,0 \mathrm{~g} / 50 \mathrm{~mL}$ de solução

Concentração $\left(\mathrm{H}_{2} \mathrm{SO}_{4}\right): 0,5 \mathrm{~N}$

Foi obtido o espectro de absorção apresentado no figura 12, para a mesma formulação do gel, mas, sem a presença da DL-Alanina. O espectro apresenta uma banda de absorção com máximo em $457 \mathrm{~nm}$. É visível a indistinguibilidade entre as respostas por absorção óptica do gel sem a adição de alanina para as diferentes doses, o que tornaria sem utilidade o gel como dosímetro.

$\mathrm{Na}$ figura 13 é apresentado o resultado das medidas de absorção óptica da mesma formulação utilizada para obtenção do resultado anterior, mas COM a adição de DL-Alanina.

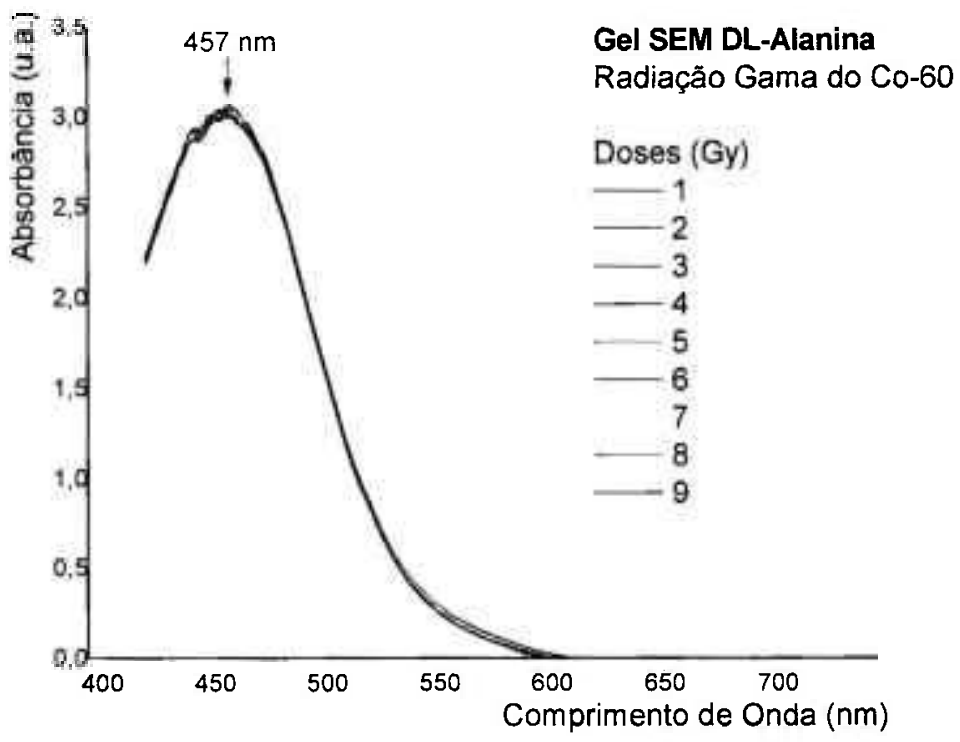

Figura 12. Espectros de absorção do gel SEM a adição de DL-Alanina em função do comprimento de onda $(\mathrm{nm})$ para diferentes doses. 


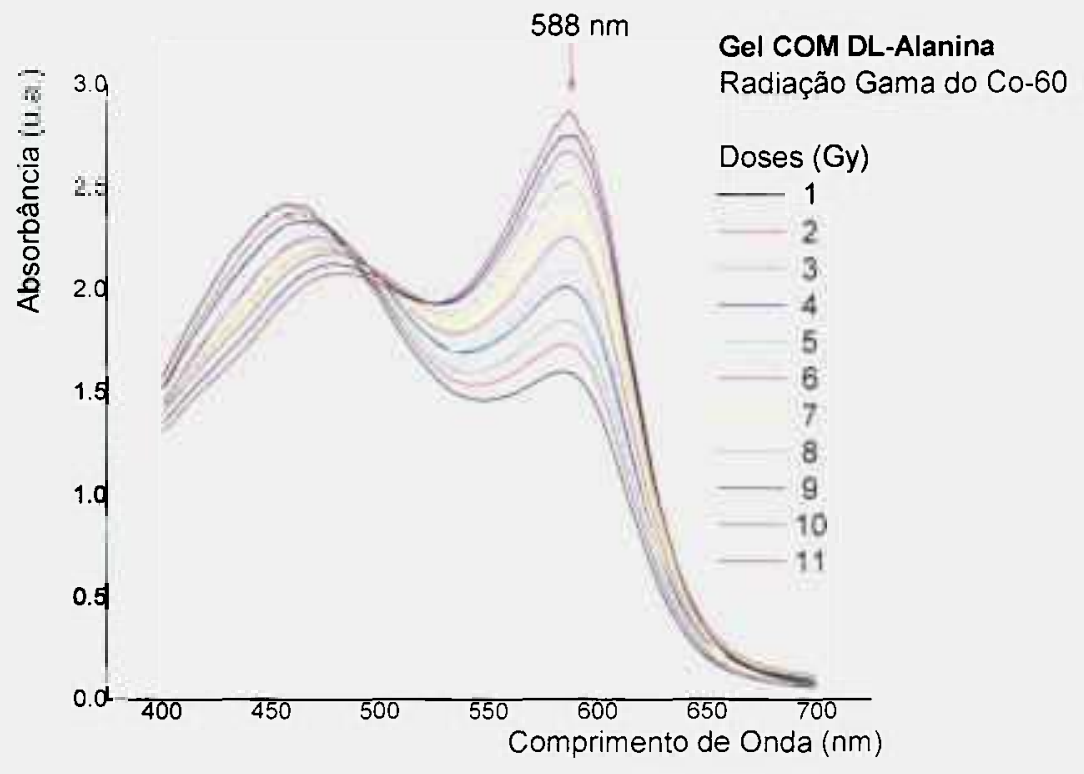

Figura 13. Espectros de absorção do gel COM a adição de DL-Alanina em função do comprimento de onda $(\mathrm{nm})$ para diferentes doses.

É nítida a diferença quando da adição da DL-Alanina na composição do gel. É fácil perceber um deslocamento do máximo de absorção da posição de $440 \mathrm{~nm}$ (SEM DL-Alanina) para $588 \mathrm{~nm}$ (COM DL-Alanina).

Esse comportamento se justifica pelo fato do $\mathrm{pH}$ desse gel se localizar numa posição central no intervalo de valores de $\mathrm{pH}$ em que se encontram equilibradas as espécies Fe-II e Fe-III. Com isso, os máximos que aparecem nas figuras 12 e 13 referem-se, respectivamente, às posições, em comprimentos de onda, onde ocorrem as máximas absorções no gel SEM e no COM DL-Alanina. O que sugere, fortemente, que a presença do aminoácido DL-Alanina favorece a criação da espécie paramagnética Ferro-III no gel dosimétrico irradiado, tornando indispensável a sua utilização para esta formulação.

Da figura 13 observa-se, a medida em que é aumentada a dose, uma gradual diminuição no pico de absorção óptica em 457 nm e proporcional aumento desta no comprimento de $588 \mathrm{~nm}$, o que sugere que, quanto maior a dose absorvida pelo sistema, mais irá diminuir o pico em $457 \mathrm{~nm}$ - pico de absorção do Fe-Il - e mais irá aumentar o em $588 \mathrm{~nm}$ - pico de absorção do $\mathrm{Fe}$ III. Dai o comportamento inversamente proporcional apresentado nesta figura 
indicando a mudança no equilíbrio do íon ferroso, Fe-ll, e do íon férrico, Fe-III. Graças a esse deslocamento no equilíbrio entre as espécimes é que se pode quantizar a dose absorvida pois esta será proporcional a tal deslocamento.

Observa-se, contudo, um ponto de cruzamento em, aproximadamente, $500 \mathrm{~nm}$. Neste ponto, observa-se que existe um equilíbrio entre as espécimes $\mathrm{Fe}$ II e Fe-III, quando avaliadas pela técnica de absorção óptica. Isso indica que, para análise neste comprimento de onda de, aproximadamente, $500 \mathrm{~nm}$, ambas as espécimes estão em constante equilíbrio tendo igual contribuição ao espectro por absorção óptica.

\subsection{CURVA DE DOSE-RESPOSTA}

A próxima etapa consistiu em estudar o intervalo de linearidade da resposta à radiação do gel de alanina feito com gelatina de origem suína, tipo ácida. Para tal, foram feitas irradiações de amostras do gel acondicionadas nas cubetas com doses entre 1 e $50 \mathrm{~Gy}$, usando sempre a irradiação de um conjunto de 3 cubetas para cada dose, posicionadas a uma distância de $20 \mathrm{~cm}$ da fonte e taxa constante de dose de 112,1 Gy/h (Setembro/2006) no ar.

A partir da irradiação das amostras neste arranjo foram obtidas as curvas de absorvância apresentadas na figuras, 14 e 15 sendo estes os resultados de uma medida das três cubetas e considerado o valor médio. Já, na etapa do levantamento das curvas Absorção vs. dose, foi utilizada a média aritmética sobre as 4 faces da cubeta e utilizando-se 3 cubetas. 


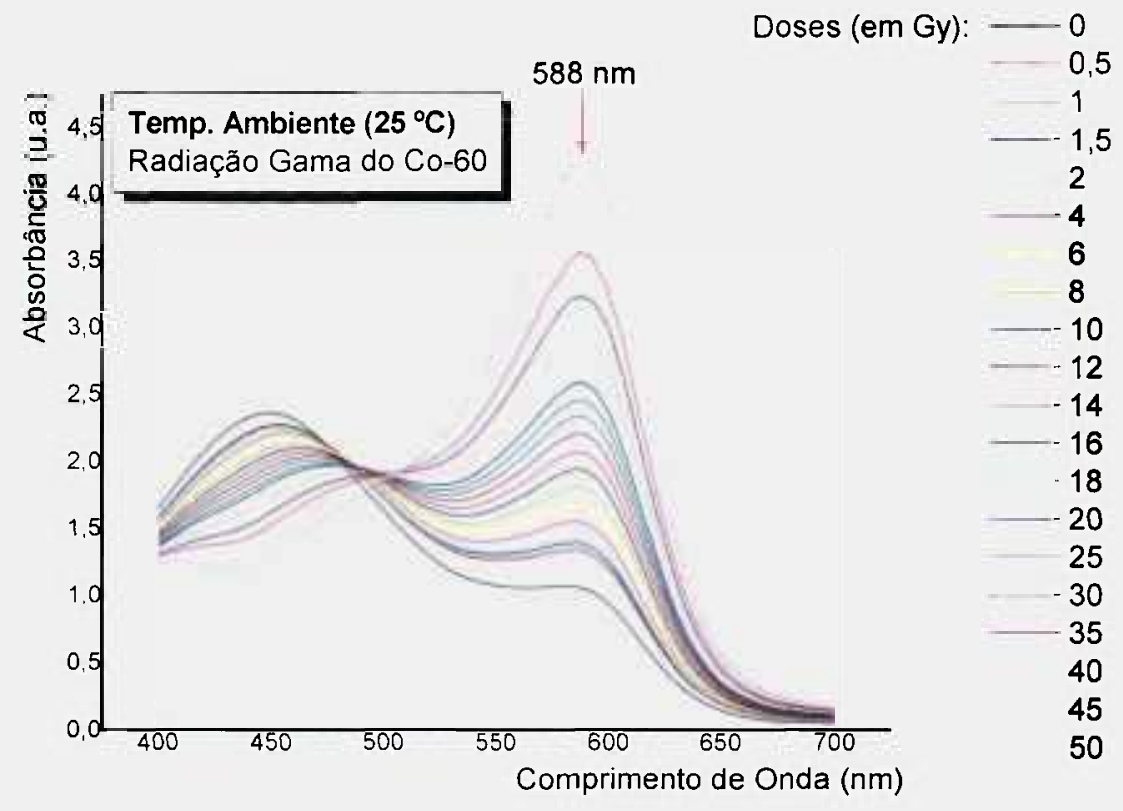

Figura 14. Espectros de absorção do gel em função do comprimento de onda (em $\mathrm{nm}$ ) para amostra não irradiada e amostras irradiadas com doses de 0,5 a $50 \mathrm{~Gy}$, em condição de equilibrio eletrônico, no ar, à temperatura ambiente para a radiação gama do Co-60.

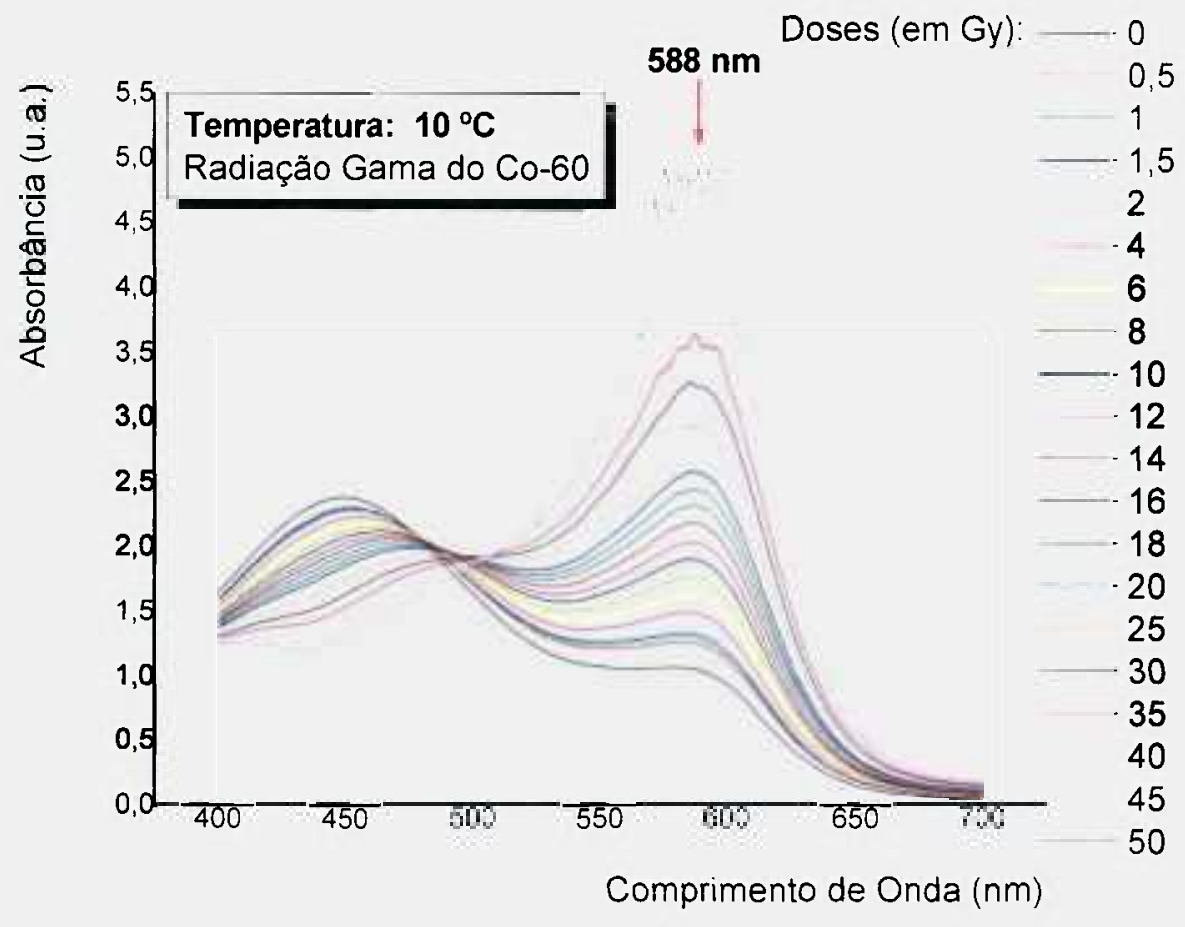

Figura 15. Espectros de absorção do gel em função do comprimento de onda (em $\mathrm{nm}$ ) para amostra não irradiada e amostras irradiadas com doses de 0,5 a $50 \mathrm{~Gy}$, em condição de equilibrio eletrônico, no ar, à temperatura ambiente para a radiação gama do Co-60. 
Os espectros apresentados na figura 14 foram obtidos após 60 minutos do final da condensação de vapor de água nas paredes da cubeta, e os espectros da figura 15 foram obtidos após 10 minutos do final desta condensação. Isso sugere que o gel necessita de um tempo de, no mínimo, uma hora após ter alcançado a temperatura ambiente para que possam ser realizadas as leituras pela técnica de espectrofotometria de absorção.

Levantando-se a curva de absorvância vs. dose a partir dos espectros apresentados na figura 14, que é o mais estável obteve-se o resultado apresentado na figura 16 .

A resposta do gel apresenta comportamento linear no intervalo de doses entre 0,5 e $40 \mathrm{~Gy}$, tendendo à saturação para doses maiores.

Os resultados obtidos, variação na tonalidade, coloração, das amostras, correspondentes ao dosímetro não irradiado e aos dosímetros irradiados com doses de 0,5 a 50 Gy podem ser percebidos a olho nu, conforme apresentado na figura 17.

\subsection{ESTABILIDADE}

Foi realizado também, o estudo da estabilidade do sinal em função do tempo (em dias) para duas situações; a primeira, mantendo o dosímetro sob refrigeração à temperatura de $5^{\circ} \mathrm{C}$ e ao abrigo da luz e na segunda, mantendo sem refrigeração e sob iluminação natural.

Os resultados podem ser observados na figura 18 através do comportamento que tende à saturação para o dosímetro mantido sob condições controladas (refrigerado e no escuro), indicando um aumento gradual na concentração de Fe-III devido à oxidação natural do Fe-II com o decorrer do tempo.

No outro caso, sem controle de temperatura e à luz natural, percebe-se um comportamento variável, saturando rapidamente. Uma justificativa para esse comportamento seria devido ao fato de em diferentes dias haver oscilação de 
temperatura e luminosidade ambiente da sala onde foi mantido o dosímetro não controlado - sem refrigeração e à luz natural. Esse comportamento da resposta comprova a importância do controle das condições de armazenamento da amostra.

No controlado, foi possivel a realização de ajuste e no outro, não pode ser feito nenhum ajuste devido ao comportamento instável, conforme pode ser observado na figura 18.

Os resultados observados indicam que a avaliação espectrofotométrica deve ser efetuadas de $3 \mathrm{em} 3$ dias, pelo menos.

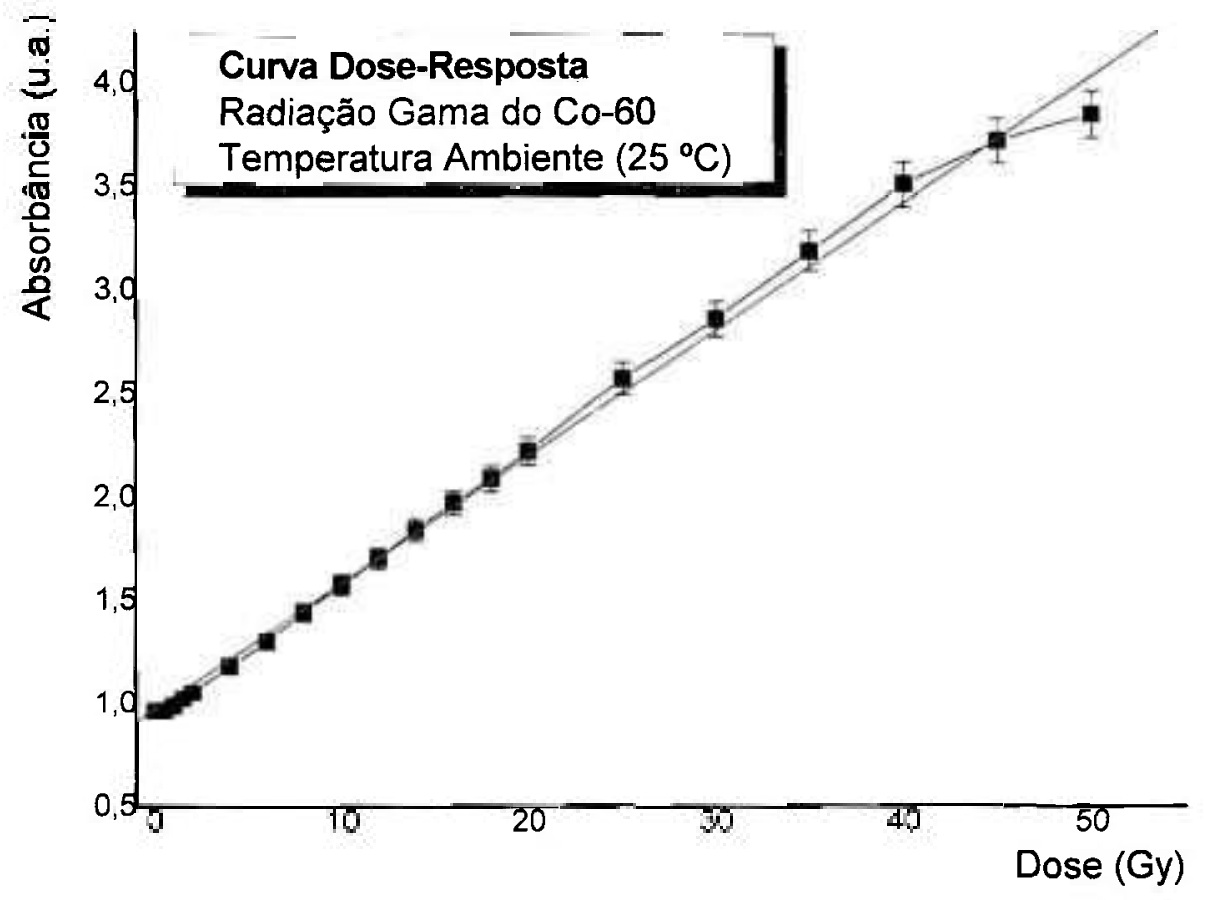

Figura 16. Curva Absorbância vs. Dose do gel de alanina para doses de radiação gama do ${ }^{60} \mathrm{Co}$ e respectivo ajuste linear.

Os dados do ajuste linear são fornecidos a seguir:

Tipo de ajuste de função: Regressão Linear

$Y=A^{*} X+B$

$\begin{array}{lll}\text { Parâmetro } & \text { Valor } & \text { Incerteza } \\ \text { A } & 0,06139 & 0,0009 \\ \text { B } & 0,96103 & 0,0218\end{array}$




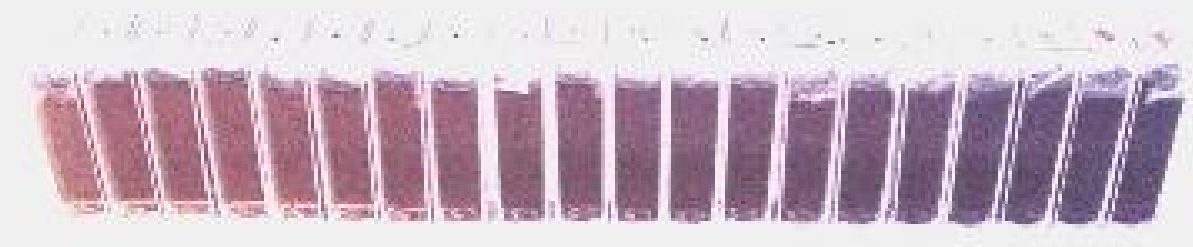

50 Gy

Figura 17. Escala de cores do gel de alanina. A cubeta não irradiada ( $0 \mathrm{~Gy}$ ) é a da extrema esquerda e a irradiada com $50 \mathrm{~Gy}$, a da extrema direita.

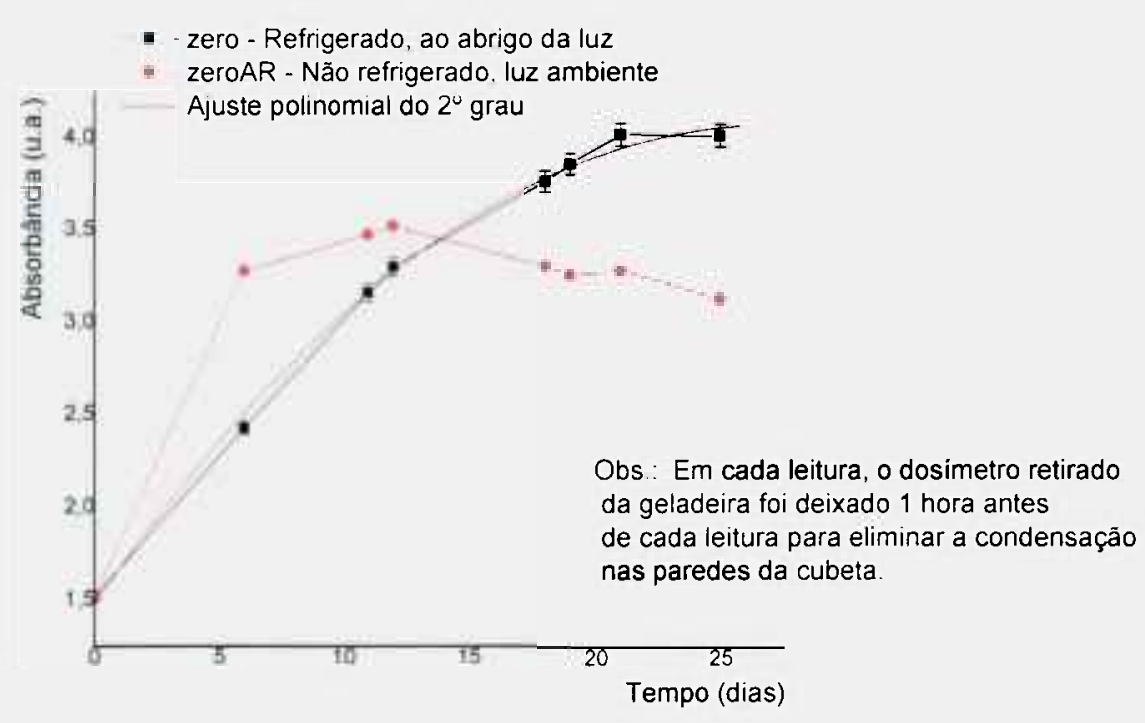

Figura 18. Comportamento comparativo das respostas dos dosímetros de alanina mantidos sob diferentes condições de armazenamento.

No conjunto de pontos correspondentes ao dosimetro mantidos sob condições controladas, foi possivel prever um comportamento que foi bem descrito por uma função de grau 2; $A(t)=-0,0034 t^{2}+0,1915 t+1,4815$ 
A variação no sinal não é significativa quando feita a observação hora-a-hora da absorção óptica, contudo, pela análise dos dados experimentais, foi encontrado o valor de $15,12 \%$ ao dia de aumento, entre o primeiro e o segundo dias. Quanto a intervalos de tempo maiores, é possivel utilizar com, excelente precisão, a função quadrática ajustada, constante no gráfico acima, até o limite de 25 dias, a partir de onde, o gel apresenta saturação.

\subsubsection{LEITURA MÍNIMA DETECTÁVEL}

Todo sistema dosimétrico necessita de uma estimativa de quão precisa e acuradamente consegue fornecer estimativas da menor dose que se pode avaliar. Para tanto, foram realizadas medidas sobre um número grande (Boas, 1966), 30 amostragens, de dosímetros Não Irradiados . Espectros estão indicados na figura 19:

Para a determinação da dose mínima detectável, foi utilizada a expressão:

$$
\text { Dose Minima }=((\overline{A . O}-b)+3 \cdot \sigma) \cdot f_{C A L}
$$

Onde: $\quad \overline{A . O} .=0,77-$ é a média aritmética sobre 30 medidas

$\mathrm{b}=0,96$ - coeficiente linear da reta ajustada

$\sigma=0,07$ - é o desvio padrão das 30 medidas

$f_{C A L}=16,29$ - é o inverso do coeficiente angular do gráfico

representado na figura 16 - unidades em $\left[\frac{\operatorname{Dose}(G y)}{\operatorname{Absorv}(U . A .)}\right]$

Resultando em:

$$
\text { Dose Mínima = 0,3 Gy }
$$

O resultado estatístico acima fornece o menor valor possível de ser obtido através do uso deste tipo de dosímetro à base da DL-Alanina-Gel, que é $0,3 \mathrm{~Gy}$ de dose absorvida. 
Observe-se que, durante o procedimento de irradiação, considerou-se a camada de equilíbrio eletrônico e na fase dos cálculos foram descontadas as doses de trânsito dos dosimetros.

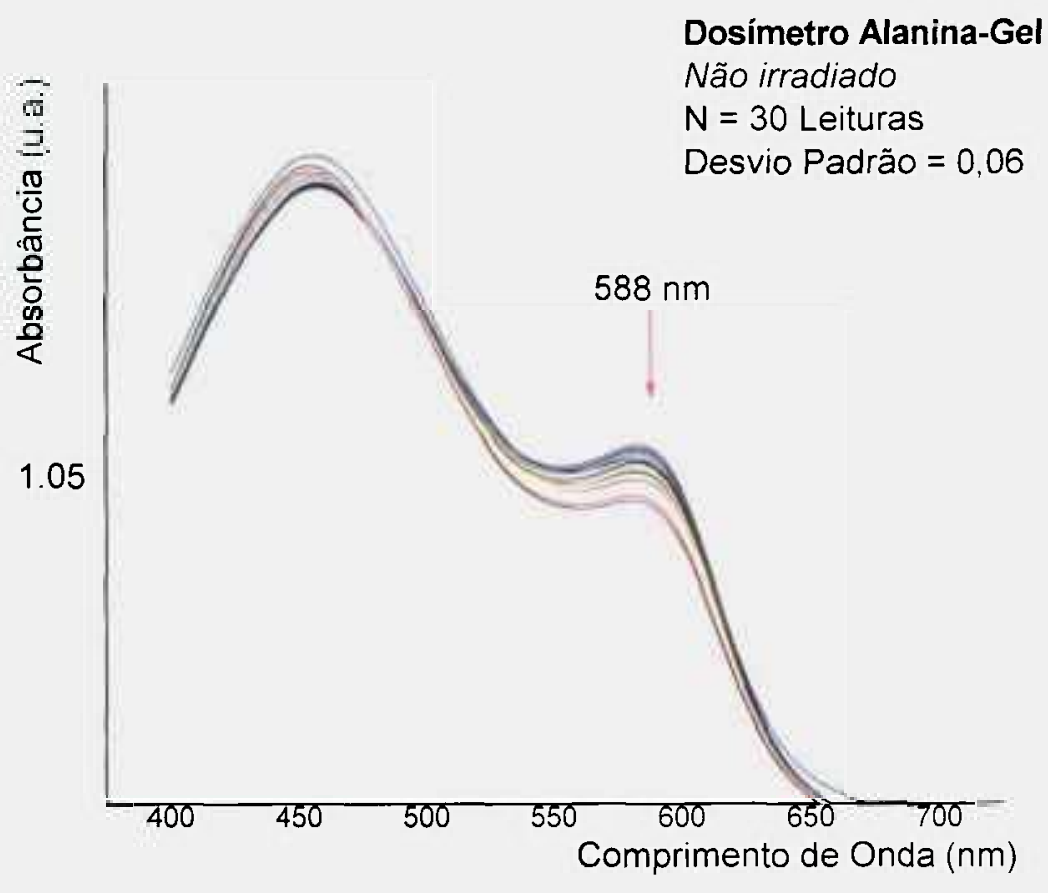

Figura 19. Espectros das 30 medições dos dosímetros de alanina, não irradiados.

A variação na amplitude em $588 \mathrm{~nm}$ deve-se à interação da Fe-ll do dosímetro com o oxigênio presente na solução, o que continua a reagir até que seja consumido todo o oxigênio presente na amostra (Cavinato, 2006).

\subsection{DEPENDÊNCIA COM A TAXA DE DOSE}

Foram realizadas leituras dos dosimetro situadas em diferentes distâncias da fonte emissora. Conseqüentemente, quanto mais próximos da fonte, maior sua taxa de dose, ao passo que, quanto maior a distância, menor a taxa.

Não foi observada nenhuma variação significativa mensurável em função das diferentes taxas de dose, variando entre 20 e $140 \mathrm{~Gy} / \mathrm{h}$. Ver figura 20 . Os resultados foram obtidos quando dos ensaios das amostras inseridos dentro de um elemento simulador cilíndrico. Conforme item 5.11 . 


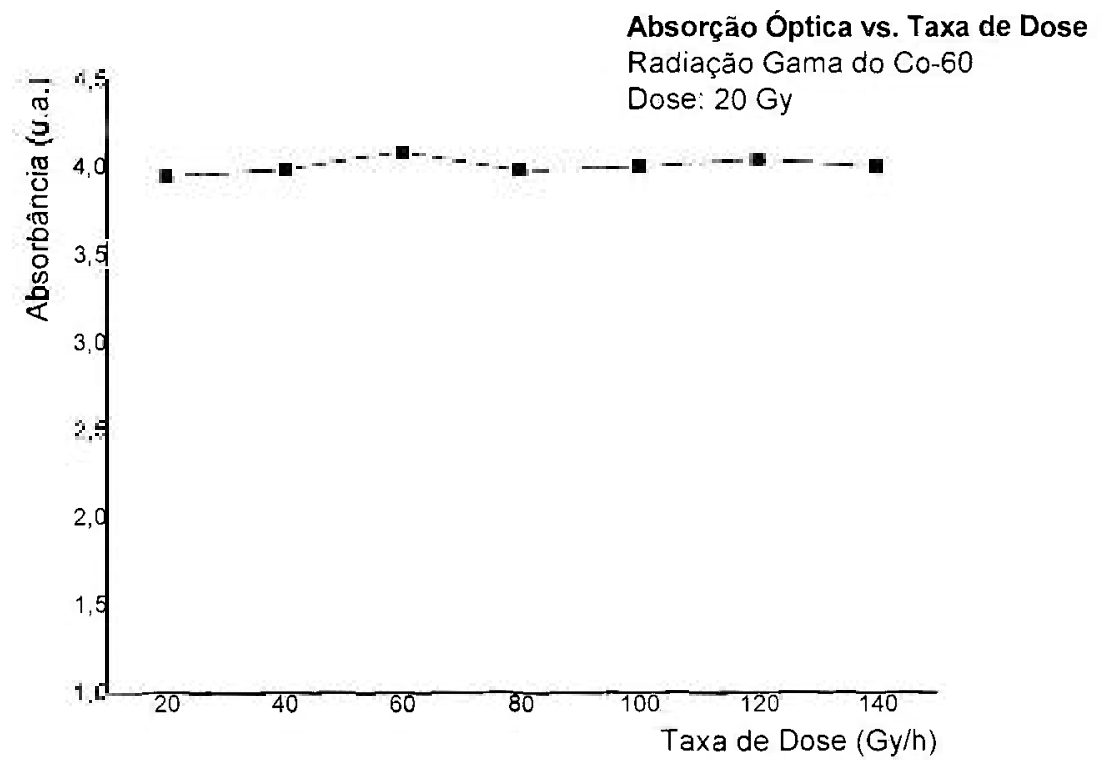

Figura 20. Estudo da dependência do sinal com a taxa de dose em Gy/h obtida em função do posicionamento em diferentes distâncias da fonte. Para a radiação gama do Co-60.

\subsection{SIMULADOR CILÍNDRICO}

Obtida a formulaçầo ideal do Gel Dosimétrico, foi confeccionado um simulador de pescoço, com o mesmo tipo de gelatina, em formato cilíndrico. Tem este a finalidade do estudo da distribuição da dose de radiação gama do Co-60 em função da posição do dosímetro no simulador. O simulador foi feito utilizando uma concentração de $50 \mathrm{~g}$ de gelatina bovina $240 \mathrm{~B}$ em $500 \mathrm{~mL}$ de água filtrada comum. Figura 21.

Não foi tomado maior cuidado com o tipo de gelatina e nem com o tipo de água, pois esse simulador não é feito de material dosimétrico e sua função é somente simular 0 tecido vivo, pois ambos são constituidos basicamente por água. Ou seja, deseja-se, somente, um meio para a colocação dos dosimetros e que tenha seu comportamento semelhante ao do tecido para efeitos da interação da radiação gama. Assim, foi utilizada a gelatina bovina e água filtrada em sua constituição. 
Foram perfuradas cavidades de $1 \mathrm{~cm}^{2}$ de secção transversal em cinco posições longitudinais em relação à direção de incidência do feixe para alocação dos dosímetro, conforme mostra a figura 21.

O simulador foi irradiado com dose de 20 Gy considerada na posição central do primeiro dosimetro, $\mathrm{A}$, em condições de equilíbrio eletrônico e à temperatura ambiente.
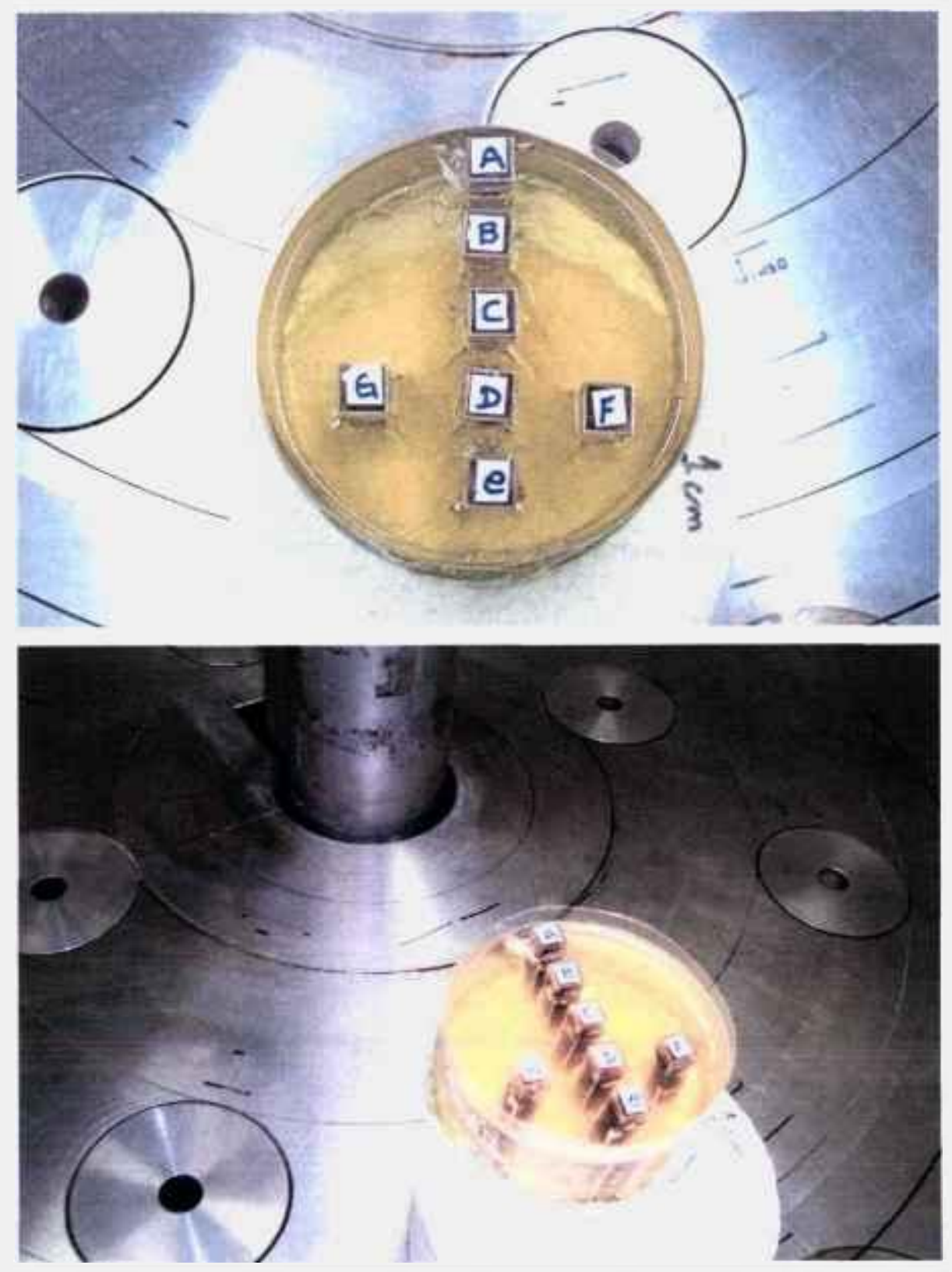

Figura 21. Simulador tecido-equivalente, contendo dosímetros de AlaninaFerro II. A distância, com precisão milimétrica, fonte-dosímetros: A a $20 \mathrm{~cm}$; B a $40 \mathrm{~cm}$; C a $62 \mathrm{~cm}$; D a $81 \mathrm{~cm}$ e E a $102 \mathrm{~cm}$. 
O primeiro dosímetro, $A$, encontra-se a $20 \mathrm{~cm}$ a partir da fonte. Os dosímetros $\mathrm{G} \mathrm{e} \mathrm{F}$, laterais ao eixo radial, forneceram leituras próximas àquelas do dosimetro $D$, central, e dentro dos limites da incerteza. Servindo, para determinar se a distribuição da radiação espalhada nas proximidades do volume irradiado é aproximadamente a mesma da do eixo central de incidência do feixe.

Feitos os cálculos e obtido um valor médio, foi observado que a dose obtida nos dosimetros laterais $\mathrm{G}$ e $\mathrm{F}$ diferem em menos de $5 \%$ da leitura obtida no dosímetro no $D$, no eixo central.

Em seguida, pronto o sistema, foi realizada a irradiação do sistema simulador considerando a dose de 20 Gy na primeira cubeta, cubeta $\mathrm{A}$. Em condições de equilíbrio eletrônico.

Esse simulador contendo os dosimetros foi irradiado com diferentes taxas de doses, entre 20 e $140 \mathrm{~Gy} / \mathrm{h}$, e não apresentou diferença nas respostas espectrofotométricas quando variado esse parâmetro. Os resultados das análises de dependência com a taxa de dose encontram-se na figura 20.

Por não apresentar alteração nos resultados, foi utilizada a taxa de dose de $112,1 \mathrm{~Gy} / \mathrm{h}$, o que correspondia na ocasião da medição a uma distância de $20 \mathrm{~cm}$ da fonte. As avaliações com espectrofotometria de absorção foram sempre feitas no mesmo comprimento de onda, $588 \mathrm{~nm}$.

Foi feito, ainda, ensaio onde foi irradiado o dosímetro central, C, sozinho no simulador, com o cuidado de preencher as cavidades anteriores com água, e irradiado com a mesma dose de 20 Gy na posição da cavidade onde estava o dosimetro $A$. Ao se comparar ambas as leituras, não foi possivel verificar diferença maior que o erro padrão.

Os espectros obtidos para esses cinco dosímetros, (dosímetros $A, B, C$, D e E), no eixo principal, são apresentados na figura 22. 
Quanto aos dosímetros nas posições transversais à de incidência do feixe, dosimetros $G$ e $F$, foram feitas as leituras e estas apresentavam a mesma leitura que o dosímetro $D$, no eixo central. Este posicionamento teve o propósito de verificar se ocorreria alguma alteração, concluindo-se, portanto, que não.

Foi observado também o comportamento para os resultados de absorvância vs. Distância para os 5 dosímetros alinhados radialmente.

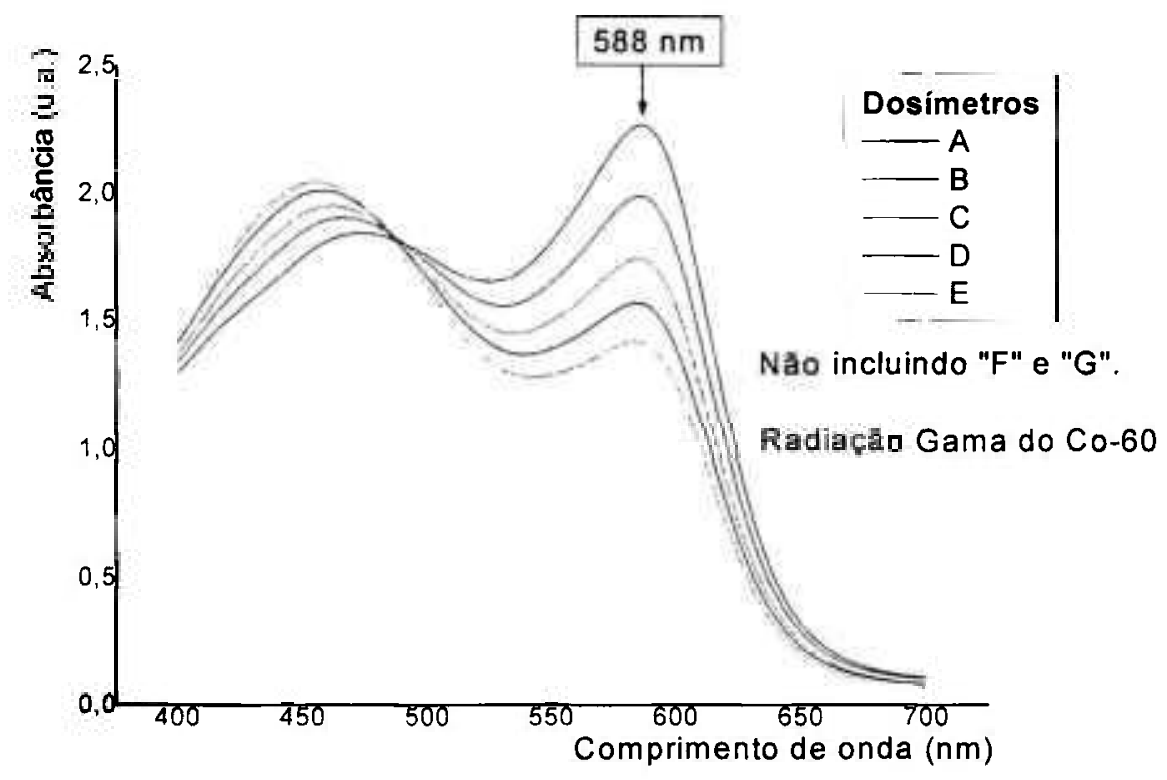

Figura 22. Espectros de absorvância para os dosimetros posicionados no simulador (no eixo principal).

A figura 23 apresenta o gráfico das leituras de absorbância para os dosímetros em função de sua distância da fonte. $O$ dosímetro $A$ está posicionado a $20 \mathrm{~cm}$ da fonte, $B$ a $22 \mathrm{~cm}, C$ a $24 \mathrm{~cm}, \mathrm{D}$ a $26 \mathrm{~cm}$ e o $\mathrm{E}$ a $28,2 \mathrm{~cm}$.

Foi obtido um ajuste exponencial decrescente, indicado na figura 23, o que está de acordo com o esperado, decaimento a medida do afastamento da fonte de radiação. 


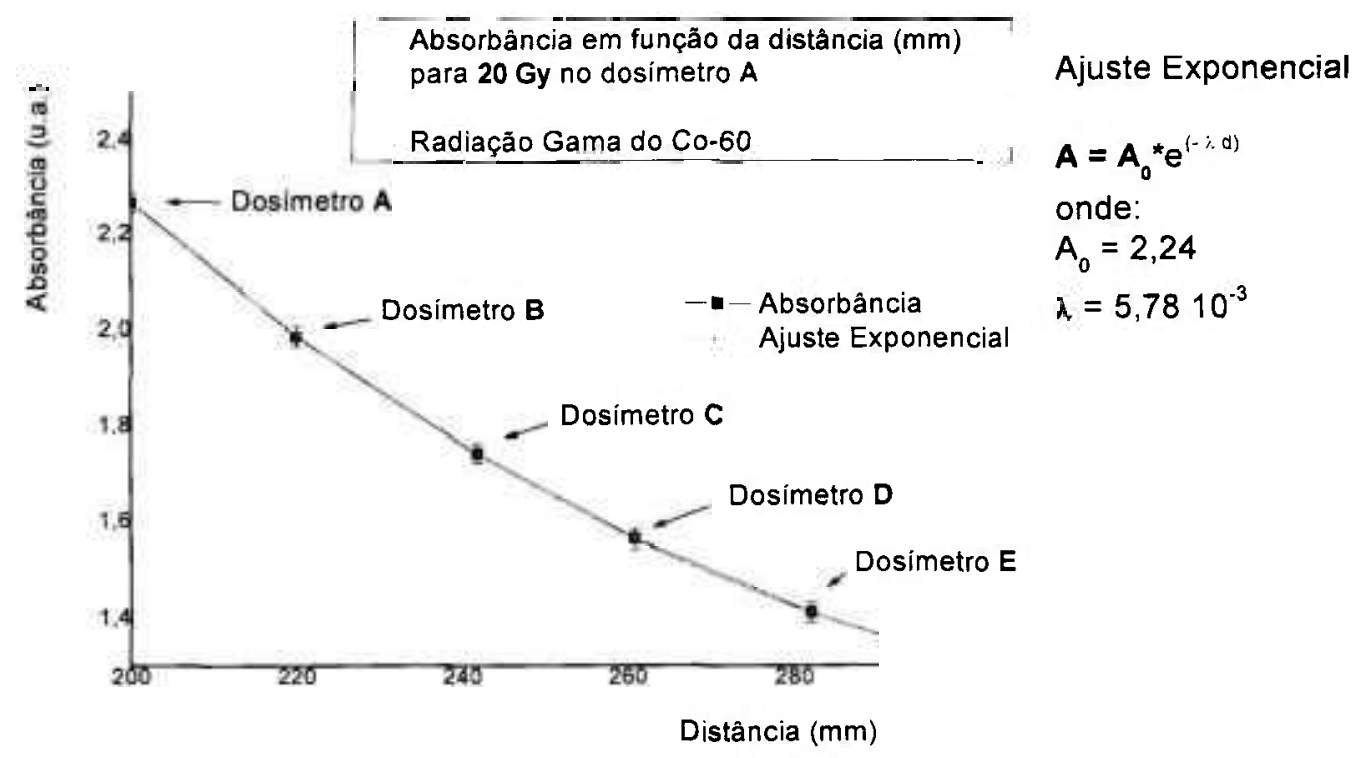

Figura 23. Valores de absorvância vs. Distância $(\mathrm{mm})$ entre a fonte e os dosimetros para dosimetria-gel posicionados no objeto simulador de gelatina. As barras de erros representam médias sobre leituras das 4 faces de cada cubeta.

$\mathrm{Na}$ figura 24 são apresentadas as doses correspondentes aos valores de absorção obtidos em função da distância fonte-dosimetro.

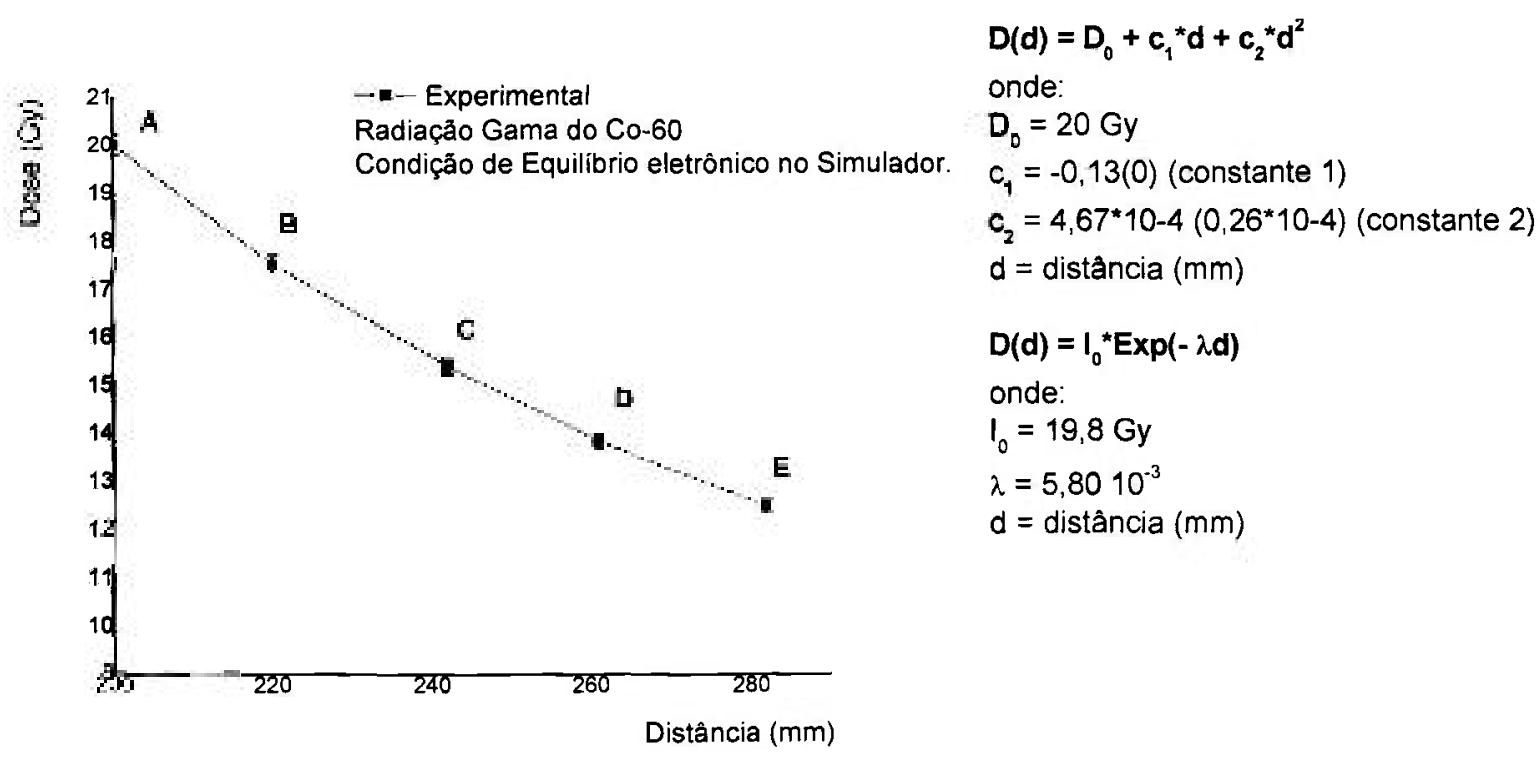

Figura 24. Valores de Dose (Gy) vs. Distância $(\mathrm{mm})$ entre a fonte e os dosímetros para dosimetria-gel posicionados no objeto simulador de gelatina. 
Foram ajustadas duas funções matemáticas distintas: a primeira, polinomial de ordem 2 e a segunda, uma exponencial.

\subsection{INCERTEZAS NA DETERMINAÇÃO DA DOSE}

As incertezas associadas às medidas das cubetas envolvem, predominantemente, o controle da condensação destas ao serem retiradas da refrigeração e submetidas à leitura. Foi sempre aguardado um período de 1 hora antes que se procedessem as leituras no espectrofotômetro.

Outra fonte considerável de incertezas é o processo de produção do material dosimétrico em forma de gel pois, primeiramente, foram dissolvidos a alanina, o alaranjado de xilenol e o sulfato ferroso amoniacal e, após ser obtida uma solução cristalina, é misturada a gelatina suína. A mistura ficou em repouso durante 20 minutos a fim de hidratar os grãos de gelatina.

Durante o processo de aquecimento, que era foi à temperatura de $100^{\circ} \mathrm{C}$, a amostra foi agitada constantemente, procurando evitar que se depositasse material no fundo da becker.

Uma vez totalmente diluído cada grão da gelatina e já homogeneizado com a solução, a amostra é posta para resfriar à temperatura ambiente e, em seguida, fracionada em cubetas para posterior irradiação e leitura.

Quanto à incerteza das leituras de uma mesma amostra pelo espectrofotometro, foi somente aquela devida pelo longo tempo entre diferentes leituras, ou seja, somente foi observada variação na resposta da absorvância quando era avaliada uma mesma amostra se fosse passado algum tempo entre uma leitura e outra. De outra forma, os resultados de absorvância eram idênticos.

\footnotetext{
Estimou-se a incerteza na determinação das amostras como a incerteza estatistica (Boas, 1966) das medidas feitas em cada cubeta, cujo valor encontrado foi $0,2 \mathrm{~Gy}$.
} 
Para tal, foi considerada para a contribuição dos erros, uma parcela associada ao erro estatístico e outra associada ao erro sistemático. Dada pela expressão:

$$
\sigma_{\text {Tenal }}^{2}=\sigma_{\text {t:sar }}^{2}+\sigma_{\text {Siscemanicos }}^{2}
$$

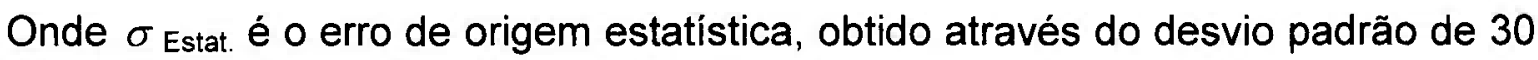
medidas de um mesmo dosímetro (cubeta) por Absorção Óptica e $\sigma$ Sistemático é o erro devido aos procedimentos adotados no processo de medida $e$, inclusive, elaboração do Gel Dosimétrico; tais como o tempo de aquecimento durante a etapa de preparo, tempo entre a irradiação e as leituras por absorção óptica e o tempo entre o final da condensação das cubetas até o momento de sua leitura.

Foi observado que as contribuições desses erros Sistemáticos (devidos à operação e elaboração) eram superiores em até 2 ordens de grandeza aos erros de origem estatística, tornando estes não significativos e adotando-se, portanto, como fonte principal de incertezas aquela devida à operação e elaboração.

Os erros sistemáticos devidos aos procedimentos foram determinados a partir de uma média realizadas em um conjunto de amostras feitas e analisadas nas mesmas condições e tirada a média, obteve-se o valor de 0,2 Gy para esta incerteza. 


\section{CONCLUSÕES}

O gel de alanina é de fácil preparação e de baixo custo, podendo ser produzido facilmente em laboratório, com excelente reprodutibilidade. A gelatina suína de altíssimo grau de pureza, apresenta um fator de consistência de 270 BLOOM e fornece todas as propriedades desejáveis para a obtenção do gel. Mais especificamente, esta gelatina, que é utilizada na indústria farmacêutica para a fabricação de cápsulas para medicamentos, não apresenta qualquer efeito de oxidação quando misturada à solução dosimétrica.

O Gel Dosimétrico apresenta excelente estabilidade quanto à consistência e resistência à temperatura mesmo quando mantido fora de refrigeração, o que é indispensável quando o que se deseja determinar, numa aplicação futura, é a distribuição de dose da radiação gama do Co-60 emitido, por exemplo, um equipamento de telecobalto, em teleterapia, onde o simulador será previamente irradiado em condições reais, e, após, submetido ao procedimento de diagnóstico por imagem de RMN que, dependendo da precisão desejada e do tamanho do volume a ser analisado, pode levar vários minutos. Desta forma, um gel que se mantenha, no intervalo de algumas horas, reprodutivel e fixo o seu campo de dose absorvida, é de grande valia para a determinação destes campos pela a técnica de RMN.

Quanto à precisão obtida, foi avaliada uma dose mínima detectável de 0,3 Gy, com uma precisão de 3 desvios padrão, ou seja, 99,99\%. Esse limite mínimo, determinado através do emprego da técnica de espectrofotometria de absorção, poderia ser reduzido ainda mais no caso do emprego com este mesmo gel da técnica de Ressonância Magnética Nuclear, o que indica de maneira clara seu efetivo potencial no emprego para a determinação dos campos de dose obtidos no procedimentos de radioterapia, com a radiação gama do Co-60.

A resposta espectrofotométrica apresenta comportamento linear no intervalo de doses aplicados em radioterapia, entre 0,5 e $40 \mathrm{~Gy}$.

O estudo da distribuição de dose empregando um simulador mostrou que podem ser avaliadas diferenças de dose da ordem de 0,3 Gy. Pois, embora 
nos ensaios tenha sido obtida uma incerteza de 0,2 Gy, no cálculo da mínima dose detectável, foi fixado o limite mínimo como sendo 0,3 Gy.

Pela análise dos dados, análise de incertezas e considerações acerca dos custos envolvidos, conclui-se que o $\mathrm{Gel}$ Dosimétrico a base de DL-Alanina desenvolvido apresenta ótimo potencial para posterior uso empregando a técnica de dosimetria tridimensional contínua, através da técnica de Ressonância Magnética Nuclear - RMN. 


\section{REFERÊNCIAS BIBLIOGRÁFICAS}

ANDERSON, C.M.; EDELMAN, P.A.; TURSKI, P.A. Clinical Magnetic Resonance Angiography. New York: Raven, 1993.

ATTIX, F.H. Introduction to radiological physics and radiation dosimetry. London.: John Willey \& Sons, 1986.

ATTIX, F.H.; ROESCH, W.C. Radiation Dosimetry. New York and London: Academic, 1968.

BAFFA, O; FERNANDES, J.P.; PASTORELLO, B.F.; ARAÚJO, D.B. Dosimetria com géis poliméricos através da relaxometria em imagens por ressonância magnética. In: XI CONGRESSO BRASILEIRO DE FÍSICA MÉDICA, Junho 14-17, 2006, Ribeirão Preto.

BERO, M.A.; GILBOY, W.B.; GLOVER, P.M. Radiochromic gel dosemeter for three-dimensional dosimetry.Radiation Physics and Chemistry, v. 61, p. 433435 (2001).

BOAS, M.L.; Mathematical Methods in the Physical Sciences. New York: Wiley \& Sons, 1966.

CAVINATO, C.C.; RODRIGUES, L..L. Estudo da estabilidade da resposta espectrofotométrica do dosímetro Fricke Gel. In: XI CONGRESSO BRASILEIRO DE FíSICA MÉDICA, Junho 14-17, 2006, Ribeirão Preto.

COSTA, Z.M. Desenvolvimento de Sistemas de DL-Alanina para dosimetria da Radiação Gama de Elétrons. 1994. Dissertação (Mestrado) - Instituto de Pesquisas Energéticas e Nucleares - IPEN/CNEN-SP, São Paulo.

Chen, F.; Martinez, A.F.; Graeff, C.F.O.; Ghillard Netto, T.; Baffa, O. Comparação teórica e experimental das curves de isodose em radioterapia usando-se dosímetro de Alanina/EPR. In: $X$ CONGRESSO BRASILEIRO DE FÍSICA MÉDICA, Maio 26-29, 2005, Salvador.

CHU, W. C. Radiation Dosimetry Using Frick-Infused Gels and Magnetic Resonance Imaging. Proc. Nucl. Sci. v. 25,1, p. 1 - 11, 2001.

CRUZ, A., CRUZ, C.M.G.S., HAMANN, J.H., SOBOLL, D.S. Resultados preliminares da distribuição de dose entre sistema de planejamento e o dosímetro de gel polimero. In: XI CONGRESSO BRASILEIRO DE FISICA MÉDICA, Junho 14-17, 2006, Ribeirão Preto.

Dainton, F.S. "Chemical Dosimetry". In PROCEEDINGS OF THE INTERNATIONAL SCHOOL OF PHYSICS, "Enrico Fermi", Course $X X X$, Radiation Dosimetry, p. 167-179, G.W. Reed ed., Academic, 1964. 
FRICKE, H.; MORSE, S. The chemical action of roentgen rays on dilute ferrous sulfate solutions as a measure of dose. Am. J. Roent. Rad. Ther., v. 18, p. 430432, 1927.

GALANTE, O.L. Padronização do Dosimetro de Alanina. 1999. Dissertação (Mestrado) - Instituto de Pesquisas Energéticas e Nucleares - IPEN/CNEN-SP, São Paulo.

Gay, C.; Collins, J.; Gebicki, M. Determination of Iron in Solutions with FerricXylenol Orange Complex. Anal. Bioch. v. 273, p. 143 - 148, 1999.

GUPTA, B.L.; BHAT, R.M.; NARAYAN, G.R.; NILEKANI, S.R. Free Radical Dosimetry by Chemical Readout. In: J.DOBO; P. HEDVIG; R.SCHLLER. Radiation Chemistry: proceedings of a symposium on ... held in Bombay, India, 1982.

GUPTA, B.L.; BHAT, R.M.; NARAYAN, G.R.; NILEKANI, S.R. A Spectrophotometric Readout Method for Free Radical Dosimetry. Radiat. Phys. Chem., v. 26(6) : p. 647-56, 1985.

GUPTA, B.L.; BHAT, R.M.; NARAYAN, G.R.; NILEKANI, S.R.; GOPAL, N.G.S.; KOVACS, A. Dose Intercomparison Using Spectrophotometric Readout Method for Free Radical Dosimetry. Appl. Radiat. Isot., v. 37(2), p. 127-30, 1986.

Horowitz, A.L. MRI Physics for Radiologists: a visual approach. 3 ed. New York, N.Y.: Springer-Verlag, 1994.

HUBELL, J.J. Photon Mass Attenuation and Energy Absorption Coefficients. Appl. Radiat. Isot., v. 33, p. $1269-1276,1982$.

IAEA. INTERNATIONAL ATOMIC ENERGY AGENCY. "CALIBRATION OF DOSIMETERS USED IN RADIOTERAPY", Tech. Rep. Series. no.: 374, Viena: IAEA, 1994. (IAEA-TECDOC-374).

INTERNATIONAL COMMISSION ON RADIATION UNITS AND MEASUREMENTS. "QUANTITIES AND UNITS IN RADIATION PROTECTION DOSIMETRY". ICRU, 1993. (ICRU-TECDOC-51).

IRIDIUM - IPN0001 - Radioproteção em Aplicações Nucleares

Notas de aula da disciplina IPN0001 ministrada no IPEN.

Disponivel em:

<www.ipn0001.iridium.com.br > Acesso em: 14 mar. 2007.

MIZUNO, E.Y.; CAMPOS, L.C. Caracterização de um gel dosimétrico à base de DL-Alanina, Ferro-II e agar-agar pela técnica de espectrofotometria. In: XI CONGRESSO BRASILEIRO DE FÍSICA MÉDICA, Junho 14-17, 2006, Ribeirão Preto. 
MORAES, C.V.; NICOLUCCI, P.; PIANOSCHI, T.A.; PELÁ, C.A. SIMULAÇÃO MONTE CARLO APLICADA À DETERMINAÇÃO DAS CURVAS DE DEPENDÉNCIA ENERGÉTICA DE UM DOSIMMETRO INDIVIDUAL TERMOLUMINESCENTE MULTI-FILTRO.. In: In: XI CONGRESSO BRASILEIRO DE FíSICA MÉDICA, Junho 14-17, 2006, Ribeirão Preto.

OLSSON, L.E.et all. Ferrous Sulphate Gels for Determination of Absorbed Dose Distribution Using MRI Technique: Basic Studies. Phys. Med. Biol., v. 34, n. 1, p. 43-52, 1989.

PALM, A.; MATTSON, O.. Influence of Sulphuric Acid Contaminants on Fricke Dosimetry. Phys. Med. Biol. v. 45, p. $111-114,2000$.

PERRIN, D.D.; Stability constants of metal-ion complexes, Part A: Innorganic ligands. IUPAC Chemical Data Series, 1979. Pergamon, 22.

PORTAL, F.; Preparation and properties of principal L products. In: OBERHOFER, M.; SCHARMANN, A. Applied Thermoluminescence Dosimetry. Bristol: Adam Hilger, p. 89-115, 1981.

SPINKS, J.W.T.;WOODS,R.J. An Introduction to Radiation Chemistry, Nes York, N.Y.: John Wiley \& Sons, 1964.

TSAI, C.H. Three-Dimensional Radiation Dosimetry Using MRI FrickeAgarose Gel Technique. 1999. Thesis (M.Sc.) - Institute of Biomedical Engineering, National Yang Ming University, Taipei, Taiwan, R.O.C.

WIKIPEDIA - THE FREE ENCYCLOPEDIA

Disponível em:

<wuw.wikipedia.org>. Acesso em: 19 maio 2007.

Van BREE NAM; IDZES, M.H.N.; HUIZENGA, H.; MIJNHEER, B.J. Film dosimetry for radiotherapy treatment planning verification of a $6 \mathrm{MV}$ tangential breast irradiation. Radiation Oncol., v. 31, p. 251-255, 1994.

VAN LAERE, K.; BUYSSE, J; BERKEVENS, P. Alanine Dosimetry Using a Spectrophotometric Ferric-Xilenol Orange Complex Readout. Radiat. Phys. Chem., v. 34 (5), p. 863-868, 1989.

VAN LAERE, K.; BUYSSE, J; BERKEVENS, P. Alanine in High-Dose Dosimetry: Spectrophotometric an Elecrochemical Readout Procedures Compared with ESR. Appl. Radiat. Isot., v. 40 (10-12), p. 885-895, 1989. 